\title{
IV Jornadas Internacionales sobre \\ Panorámica de Intervención en Altas
}

\section{Capacidades Intelectuales}

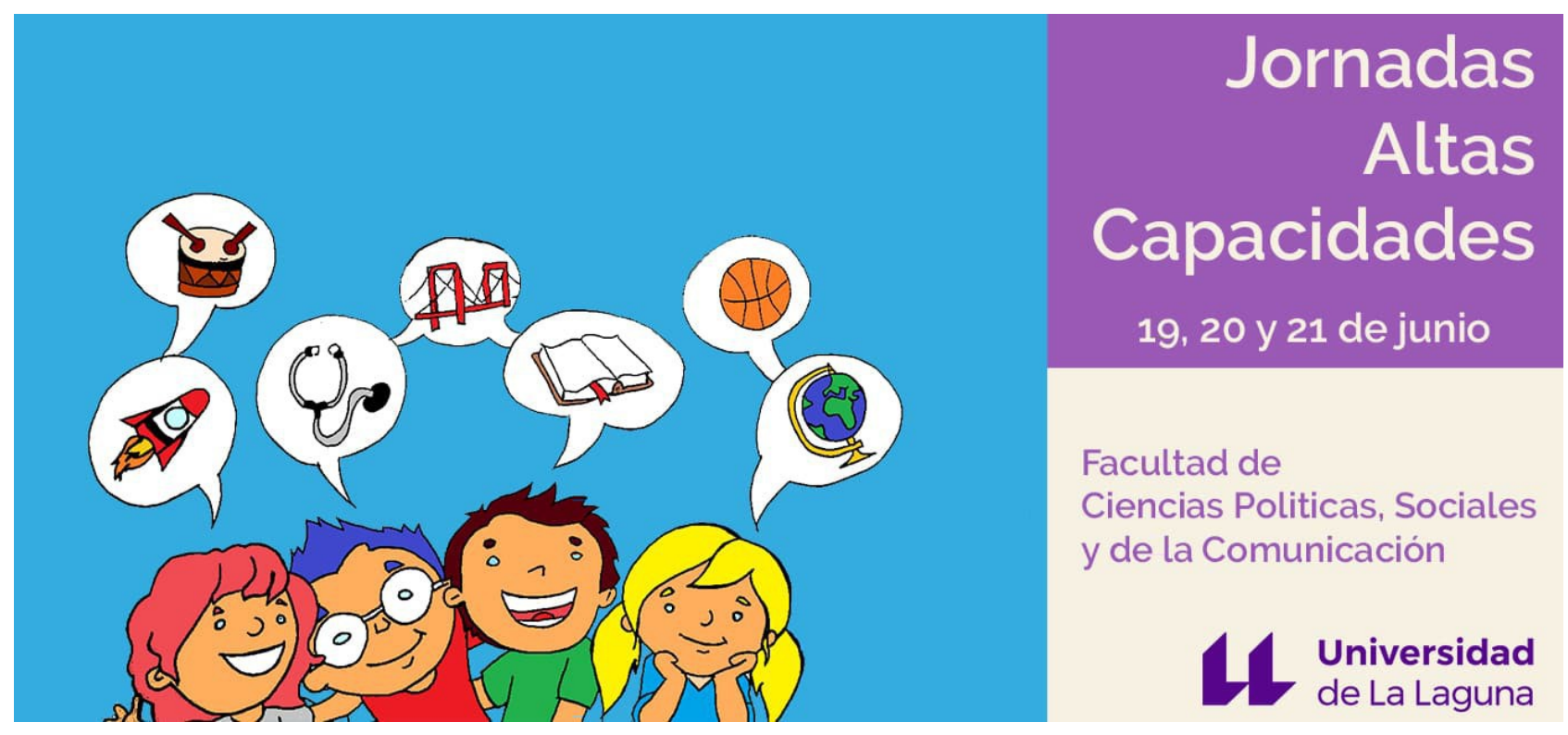

Libro de resúmenes

Universidad de La Laguna 


\title{
IV Jornadas Internacionales sobre \\ Panorámica de Intervención en Altas \\ Capacidades Intelectuales
}

\author{
Universidad de La Laguna \\ DOI:
}

https://doi.org/10.25145/b.2019.001 


\section{Colaboradores}

\section{Universidad de La Laguna}
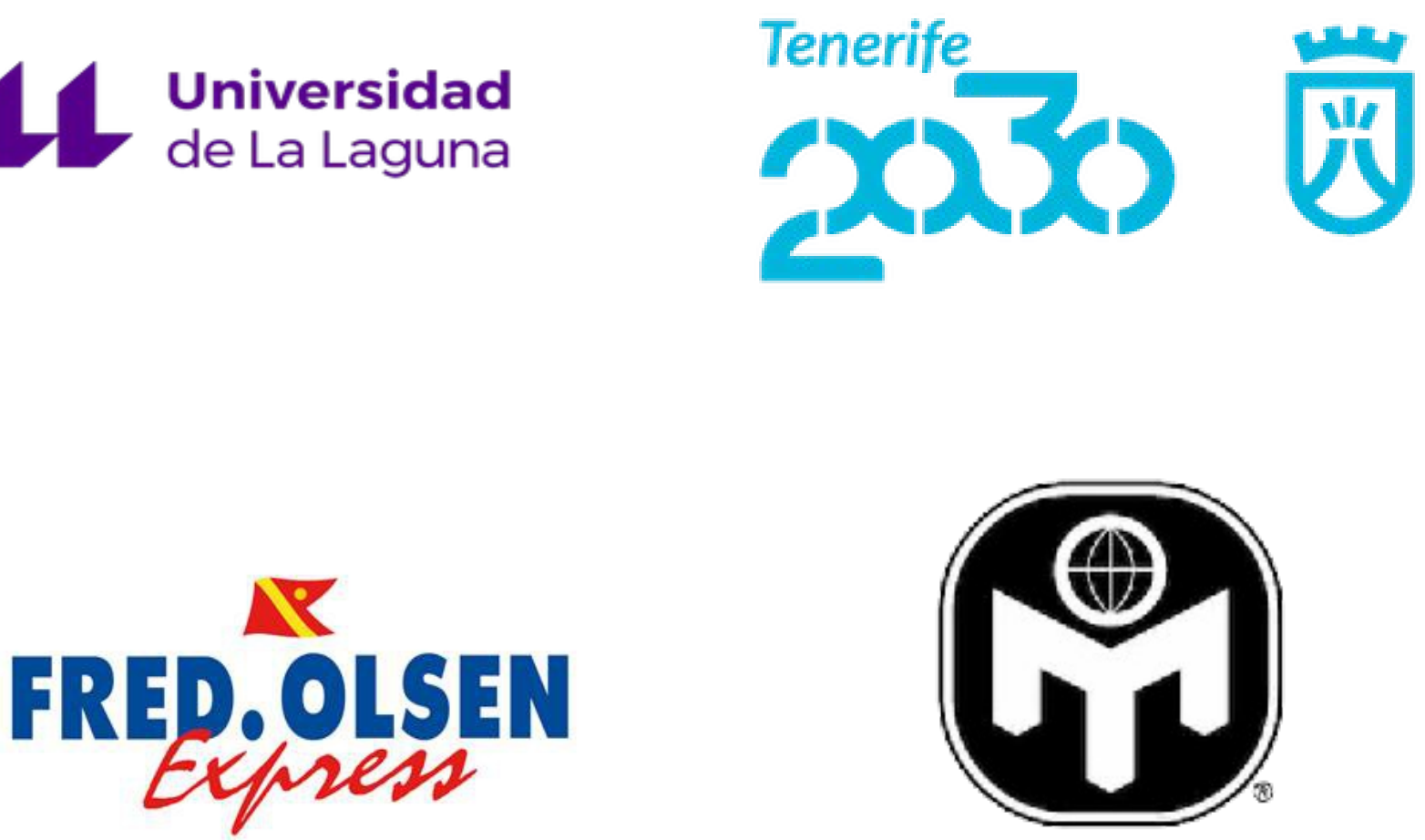

MENSAESPAÑA
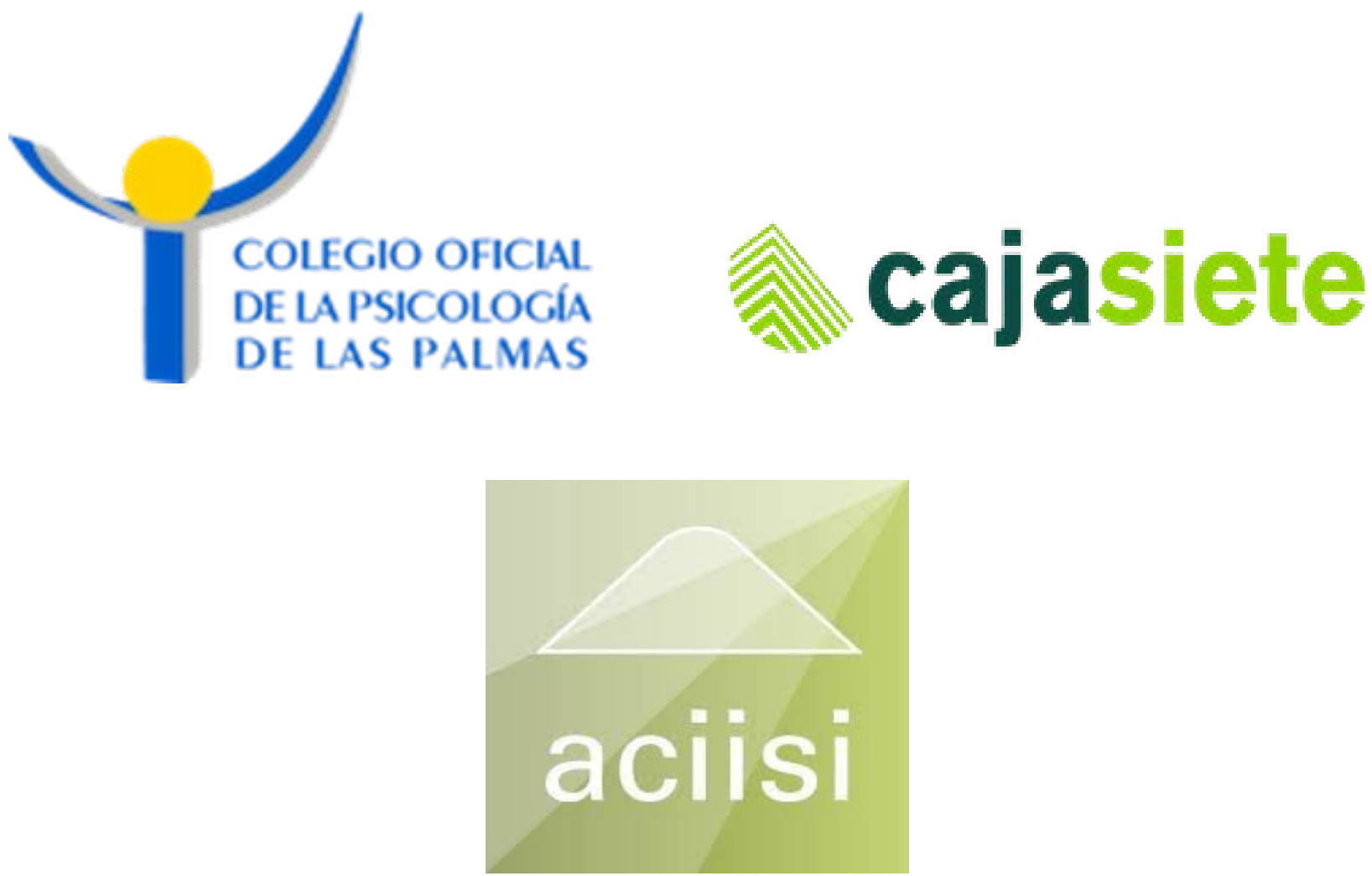


\section{Presentación}

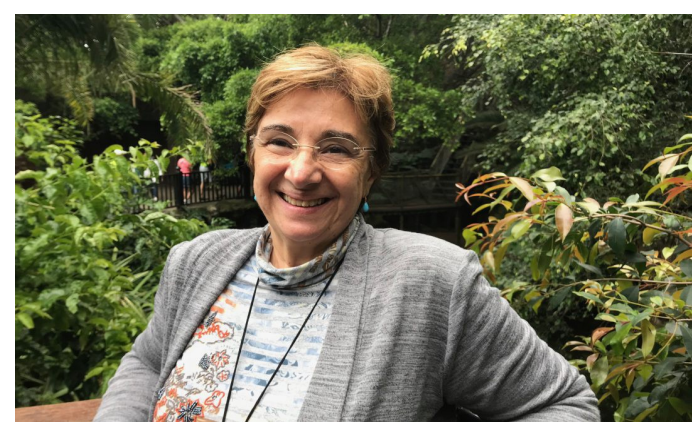

Se recogen en este libro los resúmenes de las Jornadas Internacionales sobre Panorámica de Intervención en Altas Capacidades, IV Edición. Este evento se ha consolidado, siendo un referente como encuentro intercontinental de Europa y América, con sede en la Universidad de La Laguna. Como en ediciones anteriores, se celebra en un doble formato: presencial y online.

El evento está pensado para reunir a expertos del tema de altas capacidades, pero también de difundir este conocimiento para personas del contexto de este alumnado: progenitores y profesorado. De ahí que haya una importante presencia de ponencias, impartidas por expertos, quienes, además, tienen una amplia experiencia en conducir programas de intervención en altas capacidades.

La lección inaugural, The Importance of Learning Resources in Gifted Education, está a cargo del Dr. Albert Ziegler, de la Universidad de Erlangen-Nuremberg, Alemania, con una amplia trayectoria en la investigación de las altas capacidades intelectuales, y vicepresidente de la asociación que aglutina a los expertos de este tema en Europa, el European Council for High Abilities (ECHA).

La conferencia de clausura tiene por título La respuesta educativa a las AACC en México, dictada por la Dra. María De los Dolores Valadez Sierra, de la Universidad de Guadalajara, México, con una amplia trayectoria tanto en la investigación como en el diagnóstico e intervención en altas capacidades. En la actualidad es la presidenta de Ficomundyt, asociación latinoamericana que reúne a los especialistas americanos, españoles y lusos.

Entre una y otra conferencia, se imparten 12 ponencias, dictadas por investigadores especialistas de Europa y América, con un amplio compromiso en la intervención en altas capacidades. Las investigaciones y experiencias se recogen en cuatro mesas (de diagnóstico e intervención), con 21 comunicaciones en total y en dos simposios. Finalmente, en dos mesas redondas se debate la experiencia del innovador programa para universitarios de Altas Capacidades, 
ATENEA-ULL, en su primera edición, así como la situación de las altas capacidades a nivel europeo, con participación de investigadores de España, Portugal, Alemania, Holanda e Italia.

Un evento de este tipo precisa apoyo y colaboración para llevarlo adelante. Desde aquí quiero agradecer a las entidades colaboradoras: Universidad de La Laguna, Cabildo de Tenerife, en concreto su programa Tenerife 2030, Agencia Canaria de Investigación, Innovación y Sociedad de la Información, CajaSiete, MENSA, Fred Olsen y el Colegio de Psicología de Las Palmas de Gran Canaria. Asimismo, quiero agradecer al personal de ULL-Media, que han hecho posible que se pueda realizar la versión on line del evento.

Un especial agradecimiento quiero dar a los ponentes, que se han desplazado hasta aquí para compartir sus conocimientos y experiencias. No solo porque con su presencia ayudan a difundir con rigor lo que son altas capacidades, un tema tan necesitado de desterrar mitos, sino que para todos nosotros es un encuentro fundamental, pilar de la colaboración mutua en investigaciones e iniciativas de trabajo conjunto.

También deseo expresar mi agradecimiento a los miembros del Comité Organizador, por su dedicación y profesionalidad para que este evento sea posible. A ellos se debe que el correcto funcionamiento del evento.

Finalmente quiero agradecer a la Universidad de La Laguna su compromiso con el tema de las altas capacidades. En este momento se imparten de forma estable tres programas, que abarcan todos los niveles de enseñanza. Este año se ha inaugurado también un Aula Cultural de Altas Capacidades, garantizando así una actividad continua en estos temas. El apoyo de la institución hace posible que se siga manteniendo este evento, con una periodicidad bienal.

\author{
África Borges del Rosal \\ Catedrática de Metodología de las Ciencias del Comportamiento \\ Presidenta del Comité Organizador
}




\section{Prólogo}

La atención a la diversidad en la educación superior es un deber insoslayable para las universidades. Ello incluye, por propia definición, no solo al alumnado con necesidades educativas especiales, sino también al de altas capacidades, que demanda un tipo de formación y de docencia específico y adaptado, que permita explotar todo el potencial que atesoran estos niños y niñas. Por desgracia, este colectivo no recibe con frecuencia la atención que merece no ya en la propia universidad, sino tampoco en la enseñanza primaria y secundaria.

El grupo de investigación que lidera la Dra. África Borges, catedrática de psicología de la ULL, lleva muchos años centrado en la búsqueda de herramientas y técnicas que permitan mejorar esta situación, al tiempo que en entender mejor las necesidades de aprendizaje del alumnado de altas capacidades. En los últimos años he tenido la oportunidad además de colaborar con la profesora África Borges en diferentes proyectos de carácter institucional como la iniciativa Comparte, conjuntamente con la asociación del mismo nombre, o el programa Atenea. El primero de ellos destinado a involucrar a los doctorandos/as de la ULL en la mentoría de alumnado de primaria con altas capacidades; el segundo, con el fin de mejorar la atención a los estudiantes universitarios con altas capacidades.

Fruto de este trabajo de muchos años, en el que se enmarcan los proyectos mencionados anteriormente, son también estas IV jornadas Internacionales de Intervención en Altas Capacidades Intelectuales que la ULL acoge durante el mes de junio de 2019, que persigue ofrecer información y formación sobre intervención extra e intraescolar con alumnado con Altas Capacidades Intelectuales, informar sobre diferentes aspectos teóricos de las Altas Capacidades (definición, modelos, etc.) y contribuir a la ruptura de mitos existentes en torno a las Altas Capacidades Intelectuales.

Esperamos que estas Jornadas contribuyan a mejorar la atención que se presta a este alumnado dentro del sistema educativo, y conseguir con ello realizar el enorme potencial presente y futuro de estos jóvenes tanto en el ámbito profesional como en el personal.

\section{Ernesto Pereda de Pablos}

Vicerrector de Investigación de la Universidad de La Laguna 


\section{Índice}

LECCIÓN INAUGURAL

SIMPOSIO. RESUESTA EDUCATIVA DE LA ULL A LAS ALTAS

CAPACIDADES

COMUNICACIONES LIBRES. MESA DE INVESTIGACIONES EN ALTAS

CAPACIDADES

COMUNICACIONES LIBRES. MESA DE INTERVENCIÓN I

CONFERENCIAS

SIMPOSIO. INTERVENCIÓN CURRICULAR Y EXTRACURRICULAR EN LOS ALUMNOS CON ALTAS CAPACIDADES

CONFERENCIAS

COMUNICACIONES LIBRES. MESA DE INTERVENCIÓN II

CONFERENCIAS

CONFERENCIAS

COMUNICACIONES LIBRES. MESA DE DETECCIÓN, IDENTIFICACIÓN Y EVALUACIÓN 


\section{LECCIÓN INAUGURAL}

Miércoles 19 de junio de 2019

$16: 30-17: 30$ 


\section{The Importance of Learning Resources in Gifted Education}

Albert Ziegler

My presentation focuses on a simple question that has puzzled research almost 150 years: How can education help talents to live up to their potential? In the past, education focused predominantly on the talented individuals. However, within both research and practice, there has also long been a profound interest to not only identify talented individuals but also to identify what has been described as "gifted environments", "smart contexts", or "talent hotspots". These concepts share the idea that not only do individuals differ in their potential to attain extraordinary accomplishments but also environments differ in their potential to make extraordinary accomplishments possible.

The Actiotope Model of Giftedness subscribes to a learning resource-oriented approach for talent development. These resources serve two main functions: Individual learning resources are necessary to process and make full use of environmental learning resources. Thus, for example necessitating differentiation the curriculum in formal education. In the presentation, a comprehensive categorization of learning resources is offered and implications of a learning resource orientation for talent development are discussed in relation to four areas: educational objectives of talent development, talent identification, education principles, and learning resources management. Finally, some practical examples are given. 


\section{SIMPOSIO. RESUESTA EDUCATIVA DE LA ULL A LAS ALTAS CAPACIDADES}

Miércoles 19 de junio de 2019

18:00-19:00 


\section{Presentación:}

La Universidad de La Laguna lleva una larga experiencia de 16 años apoyando la intervención educativa para el alumnado de altas capacidades, a cargo del Grupo de Investigación Aplicada en Ciencias del Comportamiento (GIACCO), a través de tres programas. El primero, Programa Integral para Altas Capacidades (PIPAC), se imparte este curso en su XVI edición, con el objetivo de contribuir al desarrollo integral del alumnado de altas capacidades, con un programa formativo de corte socioafectivo para este estudiantado y su familia. En segundo lugar, el programa COMPARTE-ULL, impulsado por la asociación Comparte y la Escuela de Doctorado y Estudios de Posgrado de la ULL (EDEPULL), que finaliza este año su segunda edición, va orientado a promover vocaciones científicas, con talleres de todas las ramas del conocimiento, con un diseño de mentorías donde estudiantes de doctorado de la ULL imparten talleres sobre el contenido de sus tesis doctorales, con un formato activo y lúdico, para alumnado de altas capacidades entre 6 y 15 años. Finalmente, este año se ha iniciado un programa para alumnado universitario de altas capacidades, ATENEA-ULL, apoyado por las entidades ya mencionadas y por el Vicerrectorado de Alumnado, que, con el objetivo de motivar a este alumnado y de abrir nuevas perspectivas, ha contado con 113 estudiantes y 75 miembros del profesorado. Se presentan en este simposio resultados de estos programas.

\section{Respuesta educativa socioafectiva: el Programa Integral para Altas Capacidades (PIPAC)}

\section{Elena Rodríguez-Naveiras}

María Cadenas

Africa Borges

El alumnado de altas capacidades intelectuales, considerado con necesidades educativas específicas, requiere de programas de intervención tanto dentro como fuera de la escuela que les ayude a desarrollar las capacidades que presentan. En la escuela no siempre reciben el apoyo que necesitan, por lo que se hace necesaria la presencia de programas extraescolares que complementen la formación de este alumnado. En el curso académico 2003-2004 se pone en marcha, en la Universidad de La Laguna, el Programa Integral para Altas Capacidades (PIPAC). Es un programa extraescolar que se implementa a lo largo del curso académico en sesiones quincenales, y tiene como objetivo el desarrollo integral del niño con alta capacidad y su familia a nivel cognitivo, socioafectivo y comportamental. El programa se divide en 3 subprogramas: descubriéndonos para 
niños de entre 3 y 12 años, tagoror para niños a partir de los 13 años y, por último encuentros para los padres y las madres. Se presentará el desarrollo de los subprogramas y la evolución del mismo así como la situación actual del programa.

\section{Evolución y desarrollo del Programa de Mentorías Comparte-ULL.}

\section{Kevin Medina Déniz}

Francisco Noda García

$M^{a}$ José Dorta

África Borges del Rosal

Manuela Rodríguez-Dorta.

El alumnado de altas capacidades presenta unas necesidades educativas que requieren una respuesta específica. Debido a esto, se han desarrollado diferentes programas que buscan satisfacer esas necesidades, como los de mentorías. Desde el curso pasado, la escuela de postgrado y doctorado de la Universidad de La Laguna en colaboración con la Asociación COMPARTE y el Grupo de Investigación Aplicada en Ciencias del Comportamiento, lleva a cabo el programa de mentorías COMPARTE-ULL, que tiene como objetivo fomentar los intereses y vocaciones científicas de los niños a través de talleres de temática diversa que son impartidos por estudiantes de doctorado de todas las áreas del conocimiento. Por ello se pretende dar a conocer la valoración de las salidas de la $2^{\circ}$ edición del programa.

\section{Evaluación de la II Edición del Programa de mentorías Comparte con la ULL}

Francisco José Noda González

María José Dorta Hernández

Jorge Sánchez

África Borges del Rosal

Manuela Rodríguez-Dorta

El alumnado de Altas Capacidades Intelectuales (AACC) presenta necesidades específicas de apoyo educativo (NEAE) que requieren de una respuesta específica. Una de ellas, puede ser la realización 
de talleres extracurriculares. El pasado mes de octubre, la Escuela de Doctorado y Estudios de Posgrado de la Universidad de La Laguna (ULL) en colaboración con la Asociación de Altas Capacidades Intelectuales de Canarias (COMPARTE) pusieron en marcha, en su segunda edición, el Programa COMPARTE-ULL que tiene como objetivo orientar e impulsar las vocaciones en diferentes áreas de conocimiento detectadas en este colectivo. El desarrollo de este programa ha supuesto un éxito por parte de alumnos y doctorandos por segundo año consecutivo. Los participantes del programa son organizados en tres grupos de edad, impartiéndose un taller una vez al mes para cada grupo. Al finalizar cada taller, responden a un cuestionario de evaluación del mismo. Éste consta de nueve ítems a los que se responde por medio de una escala tipo Likert y de una pregunta de respuesta abierta donde se hace referencia a si harían más talleres del tema impartido y por qué. Los participantes valoran positivamente los talleres, destacando la realización de más actividades del mismo tema impartido, atendiendo a distintas razones como que es afín a sus intereses o gustos y que resultan divertidos o entretenido. Sin duda, estos programas son útiles para el fomento de la curiosidad, motivación e intereses de este alumnado. Sin embargo, es necesario evaluarlos, siendo una parte importante la evaluación de la satisfacción de los usuarios.

\section{Evaluación y desarrollo del Programa de Mentoría Atenea-ULL}

\section{Manuela Rodríguez-Dorta}

Triana Aguirre Delgado

José Manuel García Fraga

África Borges del Rosal

María José Dorta

Francisco Noda

Existen diversos programas para atender a las necesidades educativas específicas del alumnado de altas capacidades intelectuales, orientados comúnmente a escolares de la etapa educativa no universitaria, principalmente Educación Infantil y Educación Primaria, mientras que el abanico de opciones ofertado al alumnado universitario más capaz resulta escaso. Por ello, y para responder a esta necesidad, el Vicerrectorado de Estudiantes de la Universidad de La Laguna (ULL) ha impulsado el Programa de Mentoría Atenea-ULL. Este Programa consta de dos tipos de actividades impartidas por docentes universitarios. Por un lado, las actividades específicas dirigidas a alumnado 
de un grado en concreto, de varios afines o abiertas a todo el alumnado participante, brindando la posibilidad de conocer aspectos de la investigación y de la realidad profesional de su área del conocimiento y/o de otras que no se abordan en el currículum ordinario, así como acercarlos al profesorado experto. Por otro lado, incluye conferencias plenarias, que ofrecen a todos una visión general sobre diversas temáticas de interés. Ambas actividades son evaluadas tanto por el alumnado asistente como por el propio profesorado que las imparte, a través de formularios de evaluación y autoevaluación online creados para cada actividad que se va desarrollando en el transcurso del Programa. Se presenta aquí el desarrollo del mismo y los resultados obtenidos en las evaluaciones y autoevaluaciones de las actividades específicas por parte de los agentes implicados, poniéndose de manifiesto el éxito del Programa, el cual resulta satisfactorio tanto para el alumnado como para el profesorado participante.

\section{¿Qué entiende el profesorado del Programa de Mentoría Atenea por Altas Capacidades?}

\section{María Silió}

África Borges

\section{Rubens Montero}

En la literatura sobre altas capacidades intelectuales no existe una definición unificada sobre lo que significa, difiriendo incluso en la forma de denominarlo (superdotación, alumnado sobresaliente, genios...). Esta falta de acuerdo afecta a quienes tienen que trabajar directamente con esta población, siendo uno de los colectivos más importantes en este sentido el profesorado. La formación sobre este tema es escasa en la enseñanza no universitaria, siendo muy infrecuente en el profesorado universitario. Por esa razón, resulta relevante conocer lo que estos docentes piensan sobre las altas capacidades. El objetivo de la presente investigación es conocer cómo conceptualizan las altas capacidades intelectuales el profesorado universitario, analizado desde una metodología cualitativa. 41 docentes respondieron a una pregunta abierta en torno a lo que consideran altas capacidades, enviado al correo electrónico del profesorado que tomó parte del Programa ATENEAULL, dirigido a estudiantes universitarios de altas capacidades de la Universidad de La Laguna. Las respuestas fueron tratadas con el programa ALCESTE, que realiza un análisis del contenido léxico. Se obtuvieron tres clases, cuyas palabras con mayor frecuencia son son habilidad, resto y coeficiente. Se concluye que el profesorado tiene una idea acertada sobre las altas capacidades que 
resulta alentadora, si bien es conveniente su capacitación para la adecuada atención al alumnado más capaz.

¿Qué entiende el alumnado universitario del Programa de Mentoría Atenea por Altas Capacidades?

Álvaro Martín

Africa Borges

Rubens Montero

Uno de los problemas con los que se enfrenta la temática de las altas capacidades es el de su conceptualización, ya que no existe una definición única de qué es lo que se entiende por ello. Las definiciones vienen mediatizadas por los modelos explicativos. Por otra parte, tampoco resulta clarificador cuáles son las características que define a este colectivo. Por ello, un acercamiento relevante es preguntar a los propios interesados cuál es la idea que tienen de alta capacidad intelectual. El objetivo de la presente investigación es conocer la concepción que el alumnado universitario de altas capacidades tiene sobre esta cuestión, mediante metodología cualitativa. La muestra estuvo compuesta por 63 estudiantes de la ULL, participantes en el programa ATENEAULL, destinado a alumnado de altas capacidades a los quienes se interrogó con una pregunta abierta sobre su idea qué es lo que constituye este concepto. Las respuestas se analizaron mediante el software ALCESTE), obteniéndose 2 clases de respuestas y siendo la segunda clase la que más aglutina respuestas, relativa a la capacidad resolver problemas, mientras que la primera se refiere a la posesión de habilidades. 


\section{COMUNICACIONES LIBRES. MESA DE INVESTIGACIONES EN ALTAS CAPACIDADES}

Miércoles 19 de junio de 2019

19:00-20:30 


\title{
Diferenciação Cognitiva entre alunos regulares e alunos com altas capacidades: Estudo com alunos do $5^{\circ}$ ao $9^{\circ}$ ano de escolaridade
}

\author{
Alberto Rocha
}

Leandro S. Almeida

Ramon García Perales

Nas últimas décadas analisou-se a sobredotação não exclusivamente definida pelo elevado quociente de inteligência (QI). Esta investigação pretende analisar diferenças nas habilidades cognitivas e nas habilidades matemáticas de adolescentes identificados ou não pelas suas altas capacidades. Esta análise diferencial, para além dos dois grupos mencionados, pretende verificar o papel nessa diferenciação de diversas funções cognitivas, e ao mesmo tempo apreciar como as mesmas poderão explicar o talento matemático dos alunos. Mais concretamente, na linha de estudos que são realizados, tomando a relação entre capacidades cognitivas e rendimento académico na disciplina de matemática, o nosso projeto pretende responder às seguintes questões: (i) que funções cognitivas melhor explicam a aprendizagem e o rendimento na matemática, diferenciando nesta disciplina diferentes componentes do currículo; (ii) que funções cognitivas e que componentes do currículo na matemática melhor explicam as diferenças nos resultados de acordo com os dois grupos de alunos em análise (com e sem sobredotação); e (iii) que impacto certas variáveis sociodemográficas poderão ter nos desempenhos cognitivos e académicos dos alunos em dois ciclos da escolaridade básica ( $2^{\circ}$ e $3^{\circ}$ Ciclos). Esta investigação é quantitativa, e segue um modelo transversal de recolha e análise da informação. Este estudo abrangerá uma amostra de 80 estudantes entre o $5^{\circ}$ e $9^{\circ}$ ano de escolaridade, 40 estudantes identificados com altas capacidades (sobredotação) e 40 estudantes não identificados como sobredotados. Assim trabalharemos com estudantes do $5^{\circ}$ e $6^{\circ}$ anos de escolaridade ( $2^{\circ}$ Ciclo do Ensino Básico) e estudantes entre o $7^{\circ}$ e $9^{\circ}$ anos de escolaridade ( $3^{\circ}$ Ciclo do Ensino Básico). A avaliação das funções cognitivas e do talento matemático inclui um conjunto heterogéneo de provas: (i) Bateria de Provas de Raciocínio (BPR), tomaremos apenas as provas de raciocínio numérico e de raciocínio verbal; (ii) Bateria de Aptidões Cognitivas (BAC), tomaremos apenas a prova de compreensão verbal; (iii) BANC - Bateria de Avaliação Neuropsicológica de Coimbra, tomaremos apenas o teste das Trilhas; (iv) Teste de Atenção D2; (v) Figura Complexa de Rey (FCR); (vi) Teste dos Cinco Dígitos (FDT); (vii) Problemas de matemática. Esperamos encontrar correlações positivas entre o raciocínio matemático e as provas que avaliam as funções cognitivas básicas, as funções executivas e os processos 
cognitivos superiores, permitindo assim compreender estas especificidades cognitivas.

\section{Validez de contenido del cuestionario de Representaciones sobre las Altas Capacidades Intelectuales (REA).}

\section{Leire Aperribai}

Josué Pérez

Africa Borges

\section{Leire Garamendi}

Introducción. La elaboración y validación de pruebas psicológicas resulta un proceso complejo que implica la consecución de una serie de criterios tanto estadísticos como teóricos a la hora de considerar un test como fiable y válido. En esta línea, son pocos los cuestionarios diseñados con la intención de apresar las representaciones que la población tiene sobre los alumnos superdotados y en muchos casos, no alcanzan valores adecuados en relación a los criterios antes mencionados resultando en pruebas con bajos valores de fiabilidad o poca validez de contenido. Los mitos y los estereotipos sobre la superdotación son habituales y es fundamental saber cómo influyen en la percepción, el diagnóstico y la intervención educativa sobre estos alumnos. Objetivo. El presente estudio analiza la validez de contenido de un nuevo cuestionario de Representaciones sobre las Altas Capacidades Intelectuales. Método. El cuestionario de Representaciones sobre las Altas Capacidades Intelectuales se creó a partir de la revisión de un cuestionario de mitos sobre la superdotación previó. Se llevó a cabo un proceso de adecuación del instrumento por medio de la revisión de la literatura y otros instrumentos similares además de la revisión y la aplicación de los criterios de expertos. Se trata de un cuestionario breve y rápido de aplicar que consta de 34 ítems con respuesta tipo Likert de 4 puntos sobre el grado de acuerdo con cada afirmación presentada. Se aplicó a un total de 511 estudiantes de magisterio. Resultados. El proceso de construcción y validación de contenido seguido en la elaboración del REA garantiza un adecuado ajuste del test a la realidad que éste pretende medir. Conclusiones. El cuestionario de Representaciones sobre las Altas Capacidades Intelectuales se muestra como adecuado y valido a nivel de contenido para su aplicación y validación como un nuevo instrumento que evalúa los conocimientos previos o representaciones que se tienen sobre el alumnado superdotado, pudiendo identificarse, de esta manera, errores, mitos o estereotipos existentes sobre éstos. 
ASPAT, Associação de Pais e Amigos para Apoio ao Talento.

\author{
Josiane Patrícia Aguiar de Carvalho
}

A responsabilidade técnica do CEDET é feita pela Associação de Pais e Amigos para Apoio ao Talento - ASPAT. É uma organização não governamental de direito civil, reconhecida de utilidade pública municipal, estadual e federal. Nasceu da necessidade de congregar a força comunitária composta por pais de crianças dotadas, professores, pesquisadores, além de outras famílias, instituições e grupos de sustentação ao programa desenvolvido pelo CEDET. Como também assistir na divulgação e expansão do ideário próprio à educação especial para desenvolvimento de capacidade e talento em nosso país. Destina-se também a apoiar e conscientizar seus associados, e a comunidade em geral, sobre a necessidade do desenvolvimento do potencial e talentos, assessorar e orientar ao processo educacional necessário a esse desenvolvimento, e conduzir estudos e pesquisas sobre educação de dotados e talentosos. Dentre seus objetivos incluem apoiar direta e indiretamente, o trabalho realizado no CEDET junto aos alunos de escolas públicas e privadas de Lavras e algumas cidades do país.

Diferencias de afrontamiento escolar entre estudiantes con $y$ sin altas capacidades intelectuales

\title{
Grecia Emilia Ortiz Coronel
}

María de los Dolores Valadez Sierra

La demanda de rendimiento escolar por su característica competitiva puede ser abrumadora para todos los estudiantes, esto ha llevado a que se estudien los efectos del estrés escolar y sus mecanismos para afrontarlo, las recientes investigaciones han demostrado que las consecuencias indeseables que afectan a los escolares sometidos al estrés son de carácter psicológico (Gaeta \& Hernández, 2009). De esta forma las estrategias de afrontamiento dan respuesta efectiva para regular los efectos de estresores que el menor pueda percibir como fuera de su control (MoralesRodríguez, Trianes, Miranda, Escobar \& Fernández-Baena, 2012). Este proceso de afrontamiento al estrés, está relacionado con la evaluación cognitiva que haga el estudiante hacia el evento (Bonny \& 
Guarino, 2001). Por sus características de personalidad y cognitivas de los niños con alta capacidad tales como una alta flexibilidad cognitiva y sus habilidades metacognitivas en comparación de sus pares se esperaría que sus estrategias de afrontamiento seas más eficientes. Por lo tanto, el objetivo del presente estudio fue conocer sí existen diferencias en el afrontamiento escolar en estudiantes con y sin alta capacidad intelectual. Participaron 114 alumnos con alta capacidad (48 mujeres [42\%] y 66 hombres [58\%]) y 212 alumnos sin alta capacidad (83 mujeres [39\%] y 129 hombres [61\%]). Se realizó una prueba estadística para comparar medias independientes, los resultados obtenidos muestran que no existen diferencias significativas en los mecanismos de afrontamiento escolar tanto en niños con y sin alta capacidad. A la luz de los resultados, se realiza la discusión.

Palabras clave: estrés, estrategias de afrontamiento, altas capacidades, alumno.

\section{Memoria-de-Trabajo en alumnos con alta capacidad intelectual}

\section{Rodríguez-Cervantes Celia Josefina}

Valadez-Sierra María de los Dolores

Verche Emilio

Soltero-Avelar Rubén

González-Betanzos Fabiola

La memoria-de-trabajo es una función que se ha relacionado con la inteligencia, con escasos estudios en altas capacidades (Sartré-Riba y Viana-Sáenz, 2016); la evaluación contribuirá en la identificación y comprensión de sus características en el contexto escolar. Evaluar la memoria-detrabajo en alumnos con alta capacidad intelectual de educación básica. Estudio cuantitativo, descriptivo, ex post-facto. Participaron 39 niños con alta capacidad intelectual (CI 136), 7-10 años, del Centro-Educativo-para-Alta-Capacidad, mediante las subpruebas de Memoria-de-Trabajo de la Batería-de-Evaluación-de-Funciones-Ejecutivas-y-Lóbulos-Frontales. Un análisis de prueba T para muestra única Statistical Package for the Social Sciences SPSS v24 mostró diferencia significativa en secuencia-máxima-Memoria-de-Trabajo-Visoespacial, tamaño de efecto grande $(\mathrm{t}(37)=4.512$, $\mathrm{p} \leq 0.005, \mathrm{r}=0.59576)$. Alumnos con alta capacidad intelectual presentan como característica diferencial mejor cantidad de información mantenida en tareas visoespaciales cuya manifestación puede estar comprometida por la carga de información verbal en el aula escolar y el nivel de ejecución promedio. 


\section{COMUNICACIONES LIBRES. MESA DE INTERVENCIÓN I}

Jueves 20 de junio de 2019

$$
\text { 9:00-10:30 }
$$


MENTORiment. La Mentoría en Contexto Universitario como Ejemplo de Enriquecimiento Extracurricular Dirigido a adolescentes con Altas Capacidades intelectuales

Rosabel Rodríguez

Amanda Far

Rocío Pérez

Desde la Universitat de les Illes Balears (UIB), y con inicio en el curso académico 2017-2018, se desarrolla MENTORiment, programa de enriquecimiento extracurricular basado en mentorías universitarias dirigidas a alumnado de Altas Capacidades Intelectuales (ACI) matriculado en $3^{\circ}$ y $4^{\circ}$ de ESO, Bachillerato y FP de las Islas Baleares. Las mentorías están guiadas por Investigadores/as y profesores/as Doctores/as de la UIB, la Escuela Superior de Arte Dramático (ESADIB), la Escuela de Arte y Superior de Diseño (EASDIB) y el Centro de Enseñanza Superior Alberta Giménez (CESAG). Se presentan los datos obtenidos de la evaluación triangulada realizada en la I edición, así como el aumento en el número de mentorías y de participantes en la II edición en curso. Se apuntan conclusiones y reflexiones para futuras ediciones.

\section{La formación de maestros y los mitos en Altas Capacidades}

\section{$M^{a}$ José Reguero González}

\section{Elena Alarcón Orozco}

Serafina Castro Zamudio

Se presenta un estudio realizado con alumnos de $2^{\circ}$ de Grado de Maestro en Educación Primaria para conocer el grado en que la formación aclara los mitos existentes sobre las altas capacidades intelectuales. Se ha administrado un cuestionario sobre mitos elaborado ad hoc, en dos fases: pre y post. En la recogida de datos del pretest, han participado 61 sujetos, 19 varones $(31,1 \%)$ y 42 mujeres $(68,9 \%)$, sin ninguna formación sobre este tema. El postest lo realizaron 60 sujetos de los 61 participantes, una vez que recibieron 5 horas de formación en altas capacidades (aclaraciones terminológicas, modelos teóricos, perfiles aptitudinales, características, respuesta educativa y programas de intervención), en la asignatura "Trastornos del desarrollo y dificultades de aprendizaje". Tras analizar los datos, se corrobora que son pocas horas de formación y, además como no se aborda directamente el tema de mitos, éstos no se aclaran e incluso se incrementan las 
dudas sobre los mismos. Por ello, sería fundamental aumentar el número de horas de formación así como abordar directamente los mitos para comprobar si, de este modo, se consiguen desterrar.

\section{Los Cicerones de GuíaMe-AC-UMA: iniciativa piloto de mentorías universitarias por y para el alumnado con Altas Capacidades Intelectuales.}

Diego Tomé Merchán

Serafina Castro Zamudio

Enrique Viguera Mínguez

$M^{a}$ Dolores García Román

$M^{a}$ Teresa Rubio Martínez

En este trabajo se presenta un estudio piloto en el que un grupo de universitarios con altas capacidades (Cicerones) realizan sesiones de mentorías para el alumnado de Secundaria con altas capacidades (participantes en el programa GuíaME-AC-UMA), en la que abordan temas relacionados con sus itinerarios académicos, estudios universitarios, becas y comparten experiencias relacionadas. Se ha administrado un cuestionario elaborado ad hoc, tanto a los Cicerones como a los alumnos del programa GuíaMe-AC-UMA. En total han participado 6 Cicerones y 9 estudiantes de GuíaMe. Tras analizar los datos, se constata que tanto los Cicerones como los alumnos de GuíaMe valoran de manera muy positiva la sesión, considerando ambas partes que ha servido para orientar a los estudiantes de GuíaMe tanto en sus estudios actuales como en sus futuros estudios universitarios. En general, a ambas partes, la sesión les ha parecido útil y completa aunque hacen algunas sugerencias que podrían ayudar a mejorar esta iniciativa. Habría que seguir trabajando para incrementar el número de Cicerones $\mathrm{y}$, fundamentalmente, el número de alumnos del programa GuíaMe que son los principales beneficiarios de esta iniciativa pionera en España que parece resultar beneficiosa.

\section{La aplicación de la Inteligencia Artificial a las altas capacidades intelectuales.}

Raquel Lucía Pérez Brito 
El impacto que el desarrollo y la aplicación de la Inteligencia Artificial va a tener en la humanidad es un tema de actualidad que preocupa a filósofos, científicos, pedagogos, juristas, psicólogos, entre otros. Los "transhumanista" consideran que a través de los progresos de la ciencia y la biotecnología el ser humano se perfeccionará física, intelectual, emocional y el moralmente. Estas modificaciones crearán una especie "posthumana" superior a la nuestra, con seres superdotados que habrán sido seleccionados, diseñados y mejorados genéticamente. Sin embargo, la selección natural a lo largo de la historia ya nos ha proporcionado seres con altas capacidades, sin ningún mejoramiento tecnológico pero que requieren de una formación diferenciada. La Inteligencia Artificial es la gran oportunidad para las personas con altas capacidades intelectuales que podrá obtener la formación personalizada que requieren y quién sabe, quizás superarán intelectualmente a la futura especie "posthumana" de la que hablabamos.

\section{Efectos de un Programa de Orientación a Padres de Hijos con Altas Capacidades}

\section{Juan Francisco Flores Bravo}

María de los Dolores Valadez Sierra

África Borges del Rosal

Julián Betancourt Morejón

Los progenitores juegan un papel fundamental en el desarrollo del alumnado de altas capacidades. A pesar de ello, se cuenta con escasas propuestas de intervención destinadas a estos. De ahí la importancia de crear programas para ayudar a su parentalidad. Se realizó un estudio cuantitativo con el propósito de analizar los efectos en cococimientos, dinámica familiar, apoyo educativo y manejo de conductas del Programa de Orientación a Padres de Hijos con Altas Capacidades (PROPHAC). Participaron 15 padres de estudiantes con CI igual o superior a 130 que asisten al Centro Educativo para Altas Capacidades (CEPAC), de Jalisco, México, quienes respondieron un cuestionario diseñado ad hoc como pretest y postet para conocer sus conocimientos parentales en relación a las áreas académica, social, familiar y aspectos generales de las altas capacidades. Los resultados indicaron diferencias significativas en todas las áreas, obteniéndose puntuaciones más altas en el postest. 


\section{Poster:}

\section{Altas capacidades + Inteligencia Artificial $=$ Personalización del Sistema Educativo Humanismo, Trashumanismo y Posthumanismo}

\section{Raquel Lucía Pérez Brito}

El sistema educativo actual, se remonta a la época del "despotismo ilustrado" en la cual la educación se convierte en pública y obligatoria para la población infantil. Era necesario conseguir una población obediente y útil para el desarrollo de las fábricas de aquel entonces. En pleno siglo XXI nuestro sistema educativo evidencia la obsolescencia y requiere de un giro brusco para adaptarse a las circunstancias presentes y futuras de los nuevos puestos de trabajo que se están generando y se van a generar en el corto, medio y largo plazo.

Durante estos siglos el sistema educativo ha estado de espaldas a las necesidades específicas que las altas capacidades requieren tanto en los contenidos como en la velocidad de aprendizaje diferenciada. Las disincronías requieren de un aprendizaje individualizado que permita orientarles hacia los temas que realmente les motiven y atraigan con garantía de éxito. La llegada de la Inteligencia Artificial y la robótica a la formación y a la educación permite soñar con un "Sistema Educativo Personalizado" para cada estudiante sea o no de altas capacidades intelectuales. La colaboración entre el enseñante y la Inteligencia Artificial harán el trabajo de mentoría necesario para que cada alumno explore lo que le motive y a la velocidad que demande. Es previsible que los avances en esta línea educativa y formativa, permita un desarrollo exponencial de las altas capacidades que hasta ahora no se ha visibilizado. 


\section{CONFERENCIAS}

Jueves 20 de junio de 2019

10:30-12:00 


\section{Factores que influyen en la intervención con el alumnado de alta capacidad intelectual}

\section{Leire Aperribai Unamuno}

Leire Garamendi Merino

El alumnado de alta capacidad intelectual parece ser, en general, uno de los grandes olvidados de nuestra escuela inclusiva. Las voces de la diversificación y la inclusión parecen acallar cuando llegan a este colectivo. Varios factores y agentes influyen en la plena inclusión de nuestro alumnado ACI. Los más cercanos, la familia y la escuela, muestran tener dificultades para poder responder a sus necesidades y para colaborar entre ambos. La comunidad parece no estar preparada para entender a los/las niños/as ACI y es una fuente de conflictos. Los agentes que más se alejan de la realidad cotidiana, pero que deciden por ella, los técnicos administrativos y los políticos, tratan el tema con cautela. En conclusión, es necesaria la comprensión de los distintos factores y la reflexión por parte de los distintos agentes.

\section{Models and strategies for talent development: the Schoolwide Enrichment Model (Renzulli \& Reis).}

\section{Lara Milan}

In order to overcome some of the problems that historically have drawn criticism to the field of gifted education, and to avoid labelling students as 'gifted' and 'nongifted', in recent years there has been a trend promoting more flexible approaches to both identification and programming. Some scholars have suggested to replace the term 'gifted education' with 'talent development'. The purpose of the research study is to examine the effects of a programming model that was specifically designed to apply some of the technology of gifted education to the overall process of schoolwide enrichment. The model employed as the experimental treatment in the study is entitled The Schoolwide Enrichment Model (SEM, Renzulli \& Reis, 1985a). Simply stated, the vision underlying the SEM is that schools should be places for talent development (Renzulli, 1994), and some of the activities recommended for the gifted can successfully be applied to larger segments of the school population (Renzulli, 1977; Reis \& Renzulli, 1982). 
Estudiantes con altas capacidades intelectuales en riesgo de exclusión. Una mirada a los factores de contexto socioeconómicos.

\section{Gabriela López Aymes}

Los modelos socioculturales para el desarrollo de las altas capacidades o el talento coinciden en integrar factores de los contextos sociales como mediadoras o condicionantes de las necesidades y los resultados del comportamiento humano. Estos factores (familia, escuela, comunidad, cultura) en interacción con las características del propio individuo (capacidad intelectual, aptitudes específicas, motivación, creatividad), podrían determinar los productos sobresalientes y el desarrollo integral de la persona. Por lo tanto, el desarrollo de las altas capacidades está muy influenciado y determinado por dichos factores. ¿Qué pasa entonces, si descubrimos a estudiantes con alto potencial viviendo, por ejemplo, en la alcaldía con mayor número de habitantes de una ciudad capital, pero con uno de los índices de mayor marginalidad del país donde los indicadores socioeconómicos son bastante desfavorables (desempleo, trabajo poco remunerados, comercio informal...); mayor índice de violencia (ocupando el cuarto lugar de homicidios dolosos y sexto lugar de robos con violencia); y donde los servicios básicos como el suministro de agua es deficiente; donde la mayoría de los jóvenes estudia hasta la secundaria y bachillerato pero muchos no concluyen una carrera profesional o técnica por circunstancias económicas o personales y la oferta cultural es reducida? En esta comunicación analizaremos la influencia de estos factores y la posibilidad de intervención para reducir el riesgo de exclusión de los alumnos con altas capacidades. 


\section{SIMPOSIO. INTERVENCIÓN CURRICULAR Y EXTRACURRICULAR EN LOS ALUMNOS CON ALTAS CAPACIDADES}

Jueves 20 de junio

$15: 30-16: 30$ 


\section{Presentación:}

Los alumnos con alta capacidad a menudo necesitan un enriquecimiento tanto dentro como fuera del aula. Se trata de perfiles con un nivel de demanda a nivel de contenidos y una elevada necesidad de aprendizaje constante. El grupo de ponentes de este simposio presentaremos distintas propuestas, todas ellas centradas en la creatividad como eje del desarrollo de cada propuesta. También se mostrarán actividades para alumnos de distintas edades y de diferentes áreas y temáticas de aprendizaje. Además, uno de los puntos que se desarrollará es incluir el trabajo emocional en dichas muestras, pues es fundamental darles un espacio para expresarse y compartir sus hipersensibilidades entre iguales. Por supuesto, también se incluyen propuestas a partir de las herramientas 2.0 y 3.0 y en el campo de la robótica y las nuevas tecnologías, en general. Se trata de proporcionar herramientas a los profesionales de la educación para atender a los alumnos con altas capacidades.

\section{Creatividad en el currículum. Intervención en el aula ordinaria.}

\section{María Sánchez Dauder}

Mi ponencia trata sobre cómo trabajar en un aula inclusiva con alumnos de altas capacidades. De qué forma, con qué tipos de estrategias y mediante qué estilo de actividades despertamos su interés y motivación y les podemos ayudar, como docentes, a ser futuros adultos responsables. La metodología desarrollada se realiza mediante mis publicaciones, nueve ya existentesen el mercado, distribuidas por edades y que se focalizan en distintas áreas: emociones, hábitos, género, acoso escolar, creatividad y cooperación. Aspectos elementales que toda persona, adulta o no, debe tener adquiridos para viajar por la vida y sentirse feliz y adaptada.

\section{Programas de desarrollo cognitivo extracurriculares para alumnos con altas capacidades intelectuales. Centro CADIS.}

Fernández Reyes $M^{a}$ Teresa.

Los programas que se presentan están diseñados por el equipo técnico del centro CADIS. Los contenidos y materiales son de elaboración propia teniendo todos como algunos de los objetivos generales los siguientes: tomar conciencia de las habilidades que componen la inteligencia; 
reconocer la voluntad y la constancia, como elementos esenciales del éxito; ser conscientes del rol del aprendizaje en el desarrollo de la inteligencia y trabajar el ámbito socio-emocional. En su implantación se aplican metodologías innovadoras. Se trabaja a través de rutinas de pensamiento (Visible Thinkings); aprendizaje cooperativo, aprendizaje basado en problemas (PBL), el método del caso y Service Learning. Otro pilar de los programas es la educación artística; así como los proyectos inteligentes y de investigación hasta los programas "Mentor" y los workshops. En esta comunicación se desarrollarán los diferentes programas que se realizan en el centro, en un margen de edad desde los 3 años hasta los 17.

\section{AVENTURINNA Idi}

Ana Fuentesanta Hernández Ortiz

En nuestro centro diseñamos programas pedagógicos para llevar a cabo con intervenciones tanto en las aulas como fuera de ellas, trabajando con los alumnos/as de Alta capacidad. Nuestro objetivo principal es trabajar la creatividad gráfica, narrativa y en todas las áreas o asignaturas. Nuestras actividades se realizan a partir de las inteligencias múltiples, la metodología es trabajo en equipo: colaborativo y cooperativo y en otros momentos individual, para desarrollar de forma autónoma la creatividad a partir de las habilidades individuales de cada uno. Estas actividades se llevaron a cabo a partir de la tesis doctoral que mostró la creatividad como capacidad para mejorar: flexibilidad de pensamiento además de la resolución de problemas y trabajar el pensamiento lateral. Los resultados obtenidos han sido muy positivos, ya que han mejorado en la creatividad y por ende en el rendimiento de cada asignatura, además ha mejorado el clima del aula-escuela.

\section{PROGRAMA ¡BRILLA! La importancia de que se conozcan y crean en ellos mismos.}

\section{Edith Lando}

Nuestro programa, tiene como objetivo fundamental potenciar y nutrir el talento de los alumnos AACC y contempla la atención familiar individualizada siempre que los padres lo necesiten. Su desarrollo es complementario a las materias curriculares del alumno e introducimos los conceptos de modo que puedan desarrollar el pensamiento crítico y divergente, a partir de su motivación 
intrínseca. Respondemos a la demanda de entrenamiento metacognitivo y al desarrollo de la inteligencia mediante la intervención pedagógica y la psicológica al trabajar la gestión emocional, reforzando la autoestima a través de un trabajo introspectivo (autoconciencia, autoconcepto i esquema corporal) y las habilidades sociales (comunicación, empatía y las expectativas). Durante el proceso educativo se busca que el alumno flexibilice la interpretación de sucesos y retos planteados y sea capaz de encontrar significados más adaptativos, positivos y por tanto, potenciadores desde su propia forma de ser. Es, a través de las experiencias y vivencias del alumno a través de las cuales podemos inferir en su propia motivación y conseguir potenciar su Talento. Tú, puedes brillar entonces a qué esperas... ¡ibrilla! 


\section{CONFERENCIAS}

Jueves 20 de junio de 2019

$16: 30-18: 30$ 
La orientación a las familias de niños y adolescentes con altas capacidades en contextos de vulnerabilidad socioecocultural.

\section{Doris Castellanos Simons}

La orientación a las familias que tienen hijos intelectualmente sobresalientes se ha convertido en un área prioritaria en el campo de la investigación e intervención en altas capacidades. A pesar de los avances y esfuerzos permanentes en este sentido, la comprensión de la diversidad de actores, de escenarios y de contextos económicos, sociales y culturales se encuentra aún en construcción. ¿Cómo influye la diversidad sociocultural en las expectativas, creencias y actitudes de los padres, y en la identificación del alto potencial de sus hijos? ¿Cómo éstas configuran sus estrategias educativas para enriquecer el potencial de sus hijos? ¿Cómo influyen en sus necesidades de orientación? En la conferencia reflexiona sobre este factor clave para el diseño e implementación de las estrategias de orientación y apoyo a las familias de niños y adolescentes con altas capacidades intelectuales, a partir del análisis de diferentes experiencias e investigación con estas poblaciones.

Investigação sobre altas capacidades: Tendências e opções metodológicas. (Research on high ability: Trends and methological options)

Ana P. Antunes

O conhecimento sobre os alunos com altas capacidades tem implicado a realização de vários estudos sobre os mesmos. O objetivo deste trabalho é apresentar uma perspetiva sobre o estado atual da arte, mais especificamente no que toca aos interesses de investigação e tipologia de estudos realizados. Nesse sentido, realizou-se uma pesquisa sobre as publicações mais recentes, em 3 revistas da especialidade, ou seja, High Ability Studies, Talincrea e Sobredotação, utilizando dois descritores: temáticas estudadas; e tipologias de estudos. Os dados recolhidos permitem verificar a existência de diferentes temas em estudo, bem como diferentes processos metodológicos adotados na investigação. Os dados são discutidos e apresentando-se também reflexões com implicações ao nível da investigação e da intervenção. 


\section{Los padres como acompañantes de un hijo con altas capacidades}

Martínez Padilla, Graciela

La educación de un hijo no es fácil, más aún cuando se trata de un hijo con una condición especial. La mayoría de padres con hijos con altas capacidades comienzan a vivir la alta capacidad de su hijo como un verdadero problema, existen mucho mitos y estereotipos en torno a estos niños que hacen difícil que sean comprendidos, incluso hasta por sus propios padres. Sin embargo, es en el contexto familiar donde el niño con alta capacidad debe encontrar los primeros apoyos y el acompañamiento para que su potencialidad y su desarrollo emocional sean atendidos adecuadamente 


\section{COMUNICACIONES LIBRES. MESA DE}

\section{INTERVENCIÓN II}

Viernes 21 de junio de 2019

9:00-10:30 


\section{EI Programa de Desarrollo del Talento Matemático de la UPN México}

\section{Cristianne Butto Zarzar}

Adrian Aldrete Quiñones

Abraham Andrade González

Se reporta un programa de enriquecimiento extraescolar para el desarrollo del talento matemático con estudiantes, profesores y padres de familia de educación básica de la Ciudad de México y el Estado de México. El programa de enriquecimiento se desarrolla por medio de actividades con estudiantes que tienen interés en el área matemáticas con la intención de integrarlo en otras áreas del conocimiento como Ciencias, Tecnología e Ingeniería. Las actividades se dividen en talleres de matemáticas para los estudiantes, organizados en dos grupos: primaria y secundaria, se trabaja con materiales y ambientes computacionales. Simultáneamente se ofrecen talleres para padres de familia, donde se trabajan temas como comunicación en la familia, límites sanos, entre otros. Las sesiones se realizan de manera quincenal con una duración dos horas y media.

La organización de los programas de atención a las altas capacidades: CEDET (Brasil) y PIPAC (España)

Amanda Rodrigues de Souza Colozio

Rosimeire de Araújo Rangni

Africa Borges

El Centro para Desenvolvimento do Potencial e Talento (CEDET), ubicado en Lavras, Minas Gerais, Brasil, se refiere a una metodología para construir un ambiente de complementación y suplementación educacional, y apoyo al alumno dotado y talentoso, matriculado de diferentes escuelas, en múltiples sistemas y niveles de enseñanza. Por su parte, el Programa Integral para Altas Capacidades (PIPAC) ubicado en Santa Cruz de Tenerife, España, está orientado a dar una respuesta global a la formación de los alumnos con altas capacidades, siendo su objetivo el desarrollo integral de ese grupo, a nivel cognitivo, socioafectivo y comportamental. Así la presente investigación trae la organización de los programas de atención CEDET y PIPAC en Brasil y en España cuanto a sus aspectos estructurales. Como resultado, se concluye que los programas CEDET y el PIPAC son en muchos aspectos estructurales parecidos, atendiendo en una 
localidad a todos los alumnos de las escuelas y teniendo también una conexión importante con las familias, en el CEDET a través de la asociación de padres ASPAT y en el PIPAC recibiendo un programa específico para progenitores. Las diferencias son que en el CEDET la intervención es gratuita mientras que en el PIPAC la financiación corre a cuenta de las familias, y también que en el CEDET incluye identificación previa, mientras que en PIPAC vienen diagnosticados. Por lo tanto, los dos programas son referencias en sus áreas de actuación, pesar de que uno está en España y otro en Brasil, el PIPAC se torna referencia en España en sus 16 años de intervención a los niños con altas capacidades de la isla, y el CEDET es una referencia en Brasil, que se destaca en sus 26 años de trabajo con los alumnos dotados y talentosos en la ciudad de Lavras.

\section{Programas extraescolares: una alternativa a la respuesta educativa de ACC}

\section{Sonia Hernández Ramos}

Elena Rodríguez-Naveiras

Africa Borges

El alumnado con altas capacidades, considerado con necesidades educativas especiales, requiere de una respuesta educativa específica tanto dentro como fuera del aula (Colangelo and Assouline, 2009; Colangelo and Davis, 2003; Elices, Palazuelos y del Caño, 2013; Subotnik, OlszewskiKubilius y Worrell, 2011; Tourón, 2012). Para ello, es fundamental que se lleven a cabo medidas de intervención que les pueda potenciar y sea acorde a las habilidades que presentan. La intervención que se da dentro del aula no siempre da respuesta a las necesidades que tiene este colectivo. Prueba de ello es el descontento que parte de este alumnado y sus familias muestra al afirmar que la educación y formación que reciben está muy lejos de la que queda recogida en la legislación. Por esta razón, la alternativa es la realización de programas extraescolares que completan la formación de este alumnado (Borges, Rodríguez-Dorta, y Rodríguez-Naveiras, 2016; Borges, RodríguezNaveiras y Rodríguez-Dorta, 2017; Cadenas y Borges, 2017; Jen, 2017; Jen, Gentry y Moon, 2017; Kim, 2016; Rodríguez-Dorta, Rodríguez-Naveiras, y Borges, 2017). Esta investigación presenta resultados de algunos de los programas extraescolares que se realizan en España y Mexico. 
Seguimiento y evaluación del Programa de universitario de apoyo a estudiantes sobresalientes Yas Na de la Universidad Autónoma de Chiapas, México.

\section{Lilia González Velázquez}

Gabriela López Aymes

Ma. del Rosario González Velázquez

Norma Aurora Becerril Pérez

Angélica Madrid Díaz.

El propósito de este trabajo es indagar los efectos del Programa Universitario de Apoyo para Estudiantes Sobresalientes YasNa de la Universidad Autónoma de Chiapas, a cuatro años de su culminación. El programa se desarrolló de 2012 a 2014 participando 30 estudiantes (15 hombres y 15 mujeres) de 15 licenciaturas, todos cursando el séptimo semestre y con promedios académicos altos; su nivel socioeconómico era medio-bajo y tres de ellos de origen indígena. Durante dos años los participantes recibieron acompañamiento académico y psicopedagógico, una beca mensual, estancias de movilidad nacional e internacional y cursos de inglés, entre otros apoyos. Se aplicó un instrumento de seguimiento de egresados y se realizó un grupo focal. En los resultados se analizan los beneficios del programa y la importancia de la intervención para favorecer sus competencias personales y profesionales en estudiantes universitarios.

\section{La participación social de niños y niñas sobresalientes a través de aprendizaje-servicio.}

\section{Moreno García Martha Beatriz}

Ortiz Espinoza Julieta, Villalpando Álvarez Nallely Guadalupe

Ciudadanos sobresalientes es un programa de atención a niños y niñas con alta capacidad intelectual. Uno de su objetivos es favorecer el desarrollo socioemocional y participación activa en beneficio de algún grupo o de la comunidad en general. La metodología denominada AprendizajeServicio combina procesos de servicio a la comunidad, de investigación y de organización grupal. Con tal metodología es posible motivar la educación ciudadana desde acciones concretas que los propios niños proponen y ejecutan. El grupo de Ciudadanos Sobresalientes colaboró con alumnos 
ciegos o con baja visión. Llevaron a cabo practicas de sensibilización, investigaron sobre la problemática y participaron en la elaboración de audiolibros y en un video de concientización e información sobre cómo ayudar a los ciegos, enalteciendo las capacidades que desarrollan. El proyecto logró motivar, ampliar conocimientos y reflexionar sobre la diversidad, discriminación y reconocer su capacidad de participación social.

\section{¿Motivación o fuerza de voluntad?}

\section{Diana Balasanyan}

Los estudiantes con altas capacidades a veces encuentran algunas asignaturas poco amenas o irrelevantes para sus intereses, y pueden mostrar falta de motivación en estas asignaturas, mermando el resultado de aprendizaje. En la presente comunicación se explorará la relación de los factores de la motivación y fuerza de voluntad y su influencia en el resultado de aprendizaje, y se propondrá un método relevante para potenciar el aprendizaje de idiomas basado en el correcto uso de estos factores. Asimismo, se propondrá una escala de autoevaluación de dichos factores y técnicas que permitirán un mayor aprovechamiento en cada caso. La ponencia será de interés para personas que han tenido dificultades en aprender idiomas. 


\section{CONFERENCIAS}

Viernes 21 de junio de 2019

10:30-12:00 


\section{Criatividade e STEAM: Uma abordagem integrada no PEDAIS}

\section{Alberto Rocha}

O descompasso entre o que é ensinado na escola e a realidade na qual o aluno está integrado é um dos grandes desafios do século XXI. As abordagens integradas como a STEAM (Science, Technology, Engineering, Arts and Mathematics), têm sido utilizadas em diversos programas de enriquecimento escolar, implementadas através de metodologias ativas centradas no aluno como a aprendizagem colaborativa e a resolução de problemas, com enfoque no desenvolvimento da criatividade e pensamento crítico. O Programa de Enriquecimento nos Domínios da Aptidão, Interesses e Socialização (PEDAIS) é um destes programas de enriquecimento, que consiste no estudo aprofundado de temas com interesse manifesto para os alunos e que procuram corresponder à necessidade de um ritmo acelerado de aprendizagem, bem como à necessidade de resolver problemas práticos do mundo real. Neste âmbito a ANEIS- Delegação de Gondomar, tem vindo a desenvolver projetos que envolvem as ciências segundo a abordagem interdisciplinar STEAM, através de projetos integradores e temáticos, dos quais são exemplos, os projetos "Investigadores forenses em ação"; “Anda Comigo Fazer os Aviões” e o "Há Vida nos Charcos”, que oferecem uma diversidade de atividades de caráter científico, tecnológico e artístico para um público-alvo com altas capacidades, muito heterogéneo nas idades, necessidades e interesses. Os projetos STEAM têm como objetivo principal promover aprendizagens integradas e interdisciplinares nas áreas de ciências, tecnologias, artes, engenharia e matemática; desenvolver as competências do século XXI e promover competências sociais e emocionais. O método denominado STEAM surge como alternativa metodológica de educação, procurando a interdisciplinaridade, a inovação e a criatividade nos processos de ensino-aprendizagem. A avaliação das perceções dos participantes, indica que os projetos implementados foram adequados em termos de interesse, motivação e grau de desafio. 


\title{
As associações de pais e a responsabilidade governamental na organização das respostas educativas para alunos com altas capacidades
}

\author{
Lúcia C. Miranda
}

O Sistema Educativo Português, tal como os sistemas de educação implementados nos países europeus, funciona com base no princípio democrático da igualdade de oportunidades, garantindo a todos os mesmos direitos de acesso a um ensino de qualidade para que nele desenvolvam as suas competências, independentemente da sua situação financeira, familiar, das características físicas, intelectuais, raça ou religião. Tendo o Governo Português subscrito a recomendação $\mathrm{n}^{\mathrm{o}} 1248$ de Conselho da Europa e a Declaração de Salamanca ambas com data de 1994, como é que o nosso sistema educativo tem contemplado as necessidades específicas dos alunos com mais capacidades? Qual tem sido o papel do Ministério da Educação e das Associações de Pais no apoio a estes alunos? Será o quadro legal existente suficiente para dar resposta às necessidades destes alunos? Partindo do quadro legal e da investigação portuguesa disponível em bases de dados, nomeadamente artigos, teses de doutoramento e dissertações de mestrado, pretende-se com este trabalho descrever a evolução da legislação em Portugal sobre Educação Inclusiva nos últimos quarenta anos, e como esta atende às características e necessidades dos alunos com altas capacidades. Neste levantamento da produção nacional procura-se estar particularmente atentos à investigação já realizada, seus modelos teóricos e enquadramento metodológico, assim como aos instrumentos e procedimentos usados na sinalização dos alunos. Por último, procura-se apresentar algumas propostas de atuação sobre a sinalização e atendimento destes alunos nas escolas portuguesas e sobre a formação dos professores neste tema. 


\section{Educação de crianças e jovens com dotação e talento: panorama de dez anos na identificação e intervenção educativa por intermédio da metodologia do CEDET}

\section{Rosimeire dos Santos}

\section{Luciana Siqueira Rosseto Salotti}

A presente conferência tem por finalidade apresentar o trabalho desenvolvido pelo Centro para o Desenvolvimento do Potencial e Talento - CEDET Assis/SP, atuando desde 2009 na identificação e na intervenção educativa para estudantes com capacidade elevada. Por intermédio da metodologia Caminhos para Desenvolver Potencial e Talento, o processo de identificação segue duas etapas, Observação direta e Observação Assistida, a primeira, uma coleta de dados que compreende uma folha de itens com indicadores captáveis durante o período escolar e a segunda etapa consiste em ofertar oportunidades diversas para que os estudantes sinalizados em duas ou mais observação direta independente possam experimentar situações de aprendizagens e expressar seus potenciais nos vários domínios de capacidade. A intervenção educativa intencional é concretizada pelo plano individual, que contempla, para cada estudante, a direção do potencial sinalizado, as diferentes combinações de atividades grupais e individuais diversificadas, vivências e convivências com pessoas admiráveis, produtivas, ativas, respeitadas em sua área de atuação e na comunidade. $\mathrm{O}$ ambiente educativo organiza-se em áreas específicas de conteúdo, cuja subdivisão, inspirado no referencial da psicologia humanista, apoia-se nas dimensões da personalidade humana: eu, o outro e o mundo. Área de Comunicação, Organização e Humanidades, consolida a concepção do outropelo cultivo da vida social, e interrelações humanas; Área de Investigação, Ciência e Tecnologias explora o contexto no qual se vive, com vista à formação da visão de mundo; e Área da Expressão, Autoconhecimento e Criatividade lida com a esfera de vivência intrapessoal, autoconhecimento e formação pessoal. A avaliação nesses dez anos, a partir da análise dos registros de identificação, dos planos de trabalhos e dos depoimentos dos estudantes, referente ao potencial criativo, revela que o processo de identificação sinaliza o domínio de capacidade do estudante, o plano individual de trabalho, elaborado pelo estudante, aponta seu foco de interesse e a intervenção do facilitador indica as necessidades observáveis. No entanto, a análise da intervenção educativa, a partir da apreciação dos registros de atendimento e de avaliação do plano de trabalho individual em relação ao desenvolvimento do potencial sinalizado revela a necessidade de formação docente para o acompanhamento e desenvolvimento das potencialidades identificadas. 


\section{CONFERENCIAS}

Viernes 21 de junio de 2019

12:30-14:00 


\section{De alumnos talentosos a educación excelente}

\section{Lianne Hoogeveen}

Hay niños, jóvenes y también adultos con altas capacidades que tienen problemas de aprendizaje, y/o problemas sociales o emocionales. La causa de estos problemas no es tan distinta a la de los problemas de aprendizaje "reales": el sistema educativo no está adaptado las necesidades del alumno. Esto puede causar problemas, que van desde el aburrimiento hasta problemas de comportamiento desadaptación o depresión. Los profesores, padres y psicólogos que quieren mejorar la situación para estos alumnos, generalmente se plantean como primera pregunta: ¿Quiénes son? o ¿Este niño o esta niña es talentoso o no? En esta ponencia la Dra. Lianne Hoogeveen quiere someter a discusión si es que estas son las preguntas que deberíamos plantearnos. Pensando en aquellos alumnos que no muestran sus capacidades, en la representación desproporcionada de alumnos de diferentes grupos demográficos, en la diferencia entre niños y niñas; debemos pensar en otras maneras de ofrecer educación excelente a todos los alumnos, incluyendo a aquellos dotados con altas capacidades. 


\section{¿Son invisibles las Altas Capacidades?: mito o realidad}

\section{Serafina Castro Zamudio}

Con esta conferencia se pretende plantear uno de los problemas más frecuentes que nos encontramos a la hora de abordar las altas capacidades como es su invisibilidad, realmente ¿son invisibles las altas capacidades? Para responder a esta cuestión, se abordarán tres apartados fundamentales:

1. Partiremos de una definición conceptual para clarificar el término altas capacidades, ya que hay bastante confusión en la literatura científica, y los distintos perfiles aptitudinales que podemos detectar dentro de la alta capacidad como es la sobredotación, el talento simple, el talento complejo o la precocidad.

2. A continuación pasaremos a tratar alguna de las características más comunes que nos podemos encontrar en los chicos y chicas que tienen una alta capacidad, para entender que nunca se debe plantear como criterio diagnóstico pero sí puede ayudar tanto a los profesores como a los padres para saber en qué aspectos o características se deben fijar para sospechar de una posible alta capacidad. Por otro lado, es clave saber qué posibles problemas pueden estar asociados a cada una de las características que se suelen dar en el alumnado con alta capacidad debido a una no detección de la misma ya que, en ocasiones, se puede sospechar e identificar a un alumno con alta capacidad por los problemas asociados que conlleva no identificar y evaluar a edad temprana.

3. Por último se abordarán alguno de los mitos más frecuentes que nos encontramos sobre las altas capacidades y que contribuyen de manera alarmante a no hacer visible la alta capacidad así como a tener un concepto sesgado sobre la misma. 


\section{Atendimento especializado a estudantes com altas habilidades: contexto e desafios no Brasildra.}

\section{Rosemeire de Araújo Rangni}

É sabido que em diferentes períodos da civilização houve personagens que causaram grandes mudanças com suas capacidades elevadas. As demandas exigidas pela sociedade atual requer que os indivíduos tenham soluções para seus problemas. Países economicamente mais pobres, como o Brasil, necessitam que os problemas tenham soluções mais rápidas, tendo em vista a escassez em várias vias. A Educação, por meio do atendimento especializado, para estudantes com altas habilidades é seguramente um caminho promissor. Atualmente o Brasil conta com 48.455.867 de alunos e somente 22.167 identificados com altas habilidades, de acordo com o censo escolar brasileiro. Apesar do aumento expressivo das matrículas nos últimos três anos, cerca de $50 \%$, ainda é um número ínfimo, se contar as recomendações de estudos e teorias desenvolvidas na área de altas habilidades mais recentes. As políticas nacionais e documentos legais de atendimento especializado ao público alvo da Educação Especial no Brasil apontam que essa parcela de estudantes devem ter direitos a uma avaliação adequada, indicação no censo escolar, serviços desenvolvidos pela equipe escolar para o desenvolvimento dos potenciais, preferencialmente em escola regular ou em parceria com instituições especializadas. O estado de São Paulo, mais rico do país, tem uma malha estudantil de 10.057.596, apesar dessa pomposa quantidade o atendimento aos estudantes com altas habilidades são inexpressivos, contando com poucos serviços no âmbito das redes estadual, municipal e particular de ensino. Especificamente a cidade de São Carlos, onde se localiza a Universidade Federal de São Carlos, conta com 51.687 estudantes matriculados. O censo escolar indica 111 com altas habilidades, porém, há controvérsias uma vez que não são verificados serviços educacionais aos alunos, o que pressupõe indicação oficial sem o atendimento especializado. Desse modo, por meio do Grupo de Pesquisa para o Desenvolvimento do Potencial Humano (Grupoh) ancorado na Universidade Federal de São Carlos, duas iniciativas, de atividade de extensão tem sido implementadas para o apoio aos alunos e familiares: a) empoderamento à famílias de alunos com altas habilidades, desde 2016 e b) Indicação de alunos do $6^{\circ}$ e $7^{\circ}$ anos de uma escola estadual em São Carlos, desde o segundo semestre de 2018. Ambas iniciativas têm visibilizado os estudantes com altas habilidades e viabilizado possíveis atendimentos que lhes são de direito. 


\section{COMUNICACIONES LIBRES. MESA DE}

DETECCIÓN, IDENTIFICACIÓN Y EVALUACIÓN

Viernes 21 de junio de 2019

16:00-17:30 
Estilos de aprendizaje como una variable diferenciadora en el alumnado con Altas Capacidades

Rosabel Rodríguez

Xavier Pons

Este trabajo se centra en poner de manifiesto las posibles relaciones existentes entre los estudiantes con Altas Capacidades y sus estilos de aprendizaje. Para ello se utilizó el inventario VIA, que analiza 16 factores relacionados con los estilos de aprendizaje, entre estudiantes que cursaban 30 o 4o de ESO y 10 o 2o de bachillerato, con o sin Altas Capacidades, observándose diferencias significativas en 3 de los factores estudiados: la constancia, la autonomía, así como en el referido a la relación conceptual.

\title{
Falsos positivos en la identificación de Altas Capacidades Intelectuales.
}

\author{
Josué Pérez \\ Elena Rodríguez \\ Africa Borges \\ Alina Tambasco \\ Sheila Curbelo
}

Muchos son los problemas asociados al proceso de identificación y diagnóstico de alumnos con altas capacidades intelectuales, desde las dificultades asociadas a las propias características de los instrumentos de medida, hasta las planteadas a nivel teórico al considerar la inteligencia y la alta capacidad intelectual desde perspectivas muy diferentes. Así mismo el número de alumnos identificados con altas capacidades se encuentra por debajo del valor esperado de forma general, existiendo diferencias importantes en función del nivel socio-económico entre otras. La no identificación o falsos positivos en el proceso diagnóstico de niños/as que han sido señalados previamente, por el profesorado o la familia, como posibles alumnos de Altas capacidades Intelectuales es una cuestión poco estudiada y que puede aportar información relevante para el proceso de identificación de este alumnado. El presente estudio busca identificar el número de falsos positivos en una serie de diagnósticos de niños y adolescentes con altas capacidades intelectuales. Se revisaron un total de 90 diagnósticos realizados a niños y adolescentes utilizando 
como instrumentos de evaluación del Test de Matrices progresivas Raven y la escala Wechsler (WPPSI y WISC). Los resultados hallados muestran una porcentaje menor del esperado de falsos positivos frente a uno mayor del esperado en los alumnos identificados como niños de Altas Capacidades. El diagnóstico tras identificación previa del profesorado o familia obtiene mayores porcentajes de identificación y menores de falsos positivos lo que indica que éste proceso previo ayuda a modo de primer filtro y favorece una mayor identificación al valorar a alumnos ya señalados.

\section{Validez de constructo del cuestionario de Representaciones sobre las Altas Capacidades Intelectuales (REA).}

\section{Josué Pérez \\ Leire Aperribai \\ Africa Borges \\ Leire Garamendi}

El conocimiento adecuado sobre los alumnos superdotados por parte de la población resulta complicado en la medida en que existe un intenso debate a nivel científico entre numerosas definiciones y propuestas teóricas diferentes que pueden favorecer la persistencia de mitos y estereotipos sobre este fenómeno, generando confusión. El estudio de mitos sobre Altas Capacidades Intelectuales es fundamental para conocer cómo influyen en la percepción, el diagnóstico y la intervención educativa sobre estos alumnos. El presente estudio analiza la validez de constructo de un nuevo cuestionario de Representaciones sobre las Altas Capacidades Intelectuales. El cuestionario de Representaciones sobre las Altas Capacidades Intelectuales se creó a partir del proceso de adecuación de un cuestionario de mitos sobre la superdotación previo. Se trata de un cuestionario breve y rápido de aplicar que consta de 34 ítems con respuesta tipo Likert de 4 puntos sobre el grado de acuerdo con cada afirmación presentada. Se aplicó de forma masiva a un total de 511 personas, principalmente estudiantes de magisterio. El análisis factorial concluye que el REA es unidimensional, ya que el valor propio del primer factor señalado en los análisis es tres veces el segundo. Los valores del KMO y test de Batlett también se ajustan al criterio. El cuestionario de Representaciones sobre las Altas Capacidades Intelectuales se muestra como adecuado y valido a nivel de constructo para su aplicación y validación como un nuevo instrumento que evalúa los conocimientos previos o representaciones que se tienen sobre el alumnado 
superdotado, pudiendo identificarse, de esta manera, errores, mitos o estereotipos existentes sobre éstos.

\section{Altas capacidades, inclusión educativa y justicia social: una reflexión.}

\section{Lavinia Stornaiuolo}

El interés creciente hacia el fenómeno de las altas capacidades resulta una componente esencial en el debate sobre la filosofía inclusiva. Indudablemente, nuestros actuales sistemas educativos se caracterizan por una marcada complejidad y diversificación, reflejo de los cambios registrados en la sociedad como consecuencia de los crecientes movimientos migratorios que interesan el espacio europeo. Por consecuencia, la reflexión teórica orientada a la inclusión del alumnado con altas capacidades necesita una imprescindible readaptación. De hecho, si bien se haya prestado adecuada atención a la infrarrepresentación de las alumnas dentro del grupo de nuestro interés, el alumnado inmigrante y/o procedente por las minorías - asimismo grupo a riesgo de exclusión - no ha atraído análogo interés. El tema, que ha sido tratado ampliamente en la producción científica y académica de UUEE, nos pone frente a unos interrogantes esenciales para el cumplimiento de la filosofía inclusiva y de los principios de igualdad y justicia social.

Indicación de dotación y talento en niños y adolescentes de instituciones de acogidas residenciales en Tenerife

Amanda Rodrigues de Souza Colozio

Rosimeire de Araújo Rangni

Africa Borges

Ana Elba Herrera Estévez

Mónica Gonçález Rivero

Se puede prever que entre un 2 hasta $20 \%$ de la población, según los estudiosos, tiene un alto grado de talento y capacidad en alguna área. Así también, estos talentos existen en todas las populaciones, culturas y camadas sociales. En esto sentido, la presente investigación trae la indicación de dotación y talento en niños y adolescentes de instituciones de acogimiento residencial en la isla de Tenerife 
en España. Para la detección se usó una adaptación de la Hoja de Observación Directa en Sala Clase (Guenther, 2013), que consta de 32 ítem para la detección de dotación y talento. El instrumento fue aplicado en 15 centros de acogidas con 21 educadores, que tenían baja su supervisión 145 niños o adolescentes. Después de la análisis de la Hoja, si permitieron señalar 5 con posible dotación y talento, siendo 2 en Inteligencia General, 1 en Creatividad y 2 en Inteligencia Socio-Afectiva. Y también 25 niños o adolescentes con más de una indicación de inteligencia en algún de los dominios de la Hoja. Así, después de una evaluación de los 30 señalados con el instrumento MATRICES TAI, si ofertó a 9 de ellos que más si destacaron, la respuesta educativa. Así, 9 niños y adolescentes fueran indicados a los programas PIPAC y Tagoror de Universidad de La Laguna para recibir respuesta educativa específica para las altas capacidades, siendo que 2 aceptaran participar, 1 en el PIPAC y 1 en el Tagoror.

\title{
Yo sí te veo. Los avances en identificación de las Altas Capacidades en las Islas Baleares
}

\author{
Rosabel Rodríguez \\ Rocío Salas \\ Georgina Rabassa \\ Aurelia Pardo \\ Amanda Far
}

La literatura especializada coincide en la necesidad de una identificación temprana y adecuada del alumnado con Altas Capacidades Intelectuales, que permita poder dar una respuesta educativa adecuada a sus características y necesidades, además de permitir prevenir los posibles efectos negativos que por inadecuación y falta de estímulo o reto en la enseñanza, puedan llegar a experimentar. En la comunidad de las Islas Baleares, se ha puesto en marcha desde el curso 20152016 el Protocolo de identificación y evaluación del alumnado de altas capacidades intelectuales en centros escolares (Rodríguez; Rabassa; Salas y Pardo, 2015). En estos cuatro años de implantación voluntaria, del protocolo por parte de los centros, se ha conseguido no solo aumentar de manera muy significativa el número de estudiantes identificados, sino muy especialmente, que haya una mayor concienciación hacia el tema, que ha dejado de ser un desconocido para la comunidad escolar, para pasar a formar parte de manera indiscutible dentro de las medidas de atención a la diversidad. En estos momentos estamos inmersos en el reto de mejorar y garantizar la atención especializada y plena a todos y cada uno de estos estudiantes identificados. 


\section{CONFERENCIA DE CLAUSURA}

Viernes 21 de junio de 2019

18:00-19:00 


\section{La respuesta educativa a los alumnos con altas capacidades en México}

María de los Dolores Valadez Sierra

En las últimas décadas, en el ámbito educativo, se ha centrado la mirada en los alumnos con altas capacidades. De esta forma cada país ha establecido la política más acorde con su contexto que dé respuesta a las necesidades de dichos alumnos favoreciendo que desarrollen al máximo su potencial. En México la atención educativa a este alumnado inicia en 1982 y continúa hasta la fecha respaldada por políticas educativas legisladas en nuestro país desde el marco de la integración hasta la inclusión educativa. En esta presentación se abordarán todas las acciones que se han emprendido desde el Gobierno para la atención educativa a esta población en educación básica, se presentarán las políticas educativas, los diferentes conceptos utilizados a lo largo de estos años, las modalidades de atención desde el enriquecimiento curricular y extra curricular, la promoción anticipada y el agrupamiento; el surgimiento de asociaciones, grupos de investigación y publicaciones. 
PROGRAMA REDUCIDO:

\begin{tabular}{|c|c|}
\hline \multicolumn{2}{|r|}{ Miércoles 19 de junio de 2019} \\
\hline $11: 00-13: 00$ & $\begin{array}{c}\text { Taller de Enriquecimiento Social y Emocional para alumnado de AACC a } \\
\text { través de los Juegos de Rol }\end{array}$ \\
\hline $15: 00-16: 00$ & Entrega de documentación \\
\hline $16: 00-16: 30$ & Inauguración \\
\hline $16: 30-17: 30$ & $\begin{array}{c}\text { Lección Inaugural } \\
\text { The Importance of Learning Resources in Gifted Education }\end{array}$ \\
\hline $17: 30-18: 00$ & Cóctel Inaugural \\
\hline 18:00-19:00 & Simposio. Respuesta Educativa de la ULL a las Altas Capacidades \\
\hline 19:00-20:30 & Comunicaciones libres. Mesa de Investigaciones en Altas Capacidades \\
\hline
\end{tabular}

\begin{tabular}{|c|c|}
\hline \multicolumn{2}{|c|}{ Jueves 20 de junio de 2019} \\
\hline $09: 00$ a $10: 30$ & Comunicaciones libres. Mesa de Intervención $I$ \\
\hline $10: 30$ a $12: 00$ & Conferencias \\
\hline $12: 00$ a $12: 30$ & Descanso para el café/Sesión de póster \\
\hline $12: 30$ a $14: 00$ & Mesa redonda. Programa de Mentoría Atenea-ULL \\
\hline $15: 30$ a $16: 30$ & Simposio. Intervención curricular y extracurricular en los alumnos con altas \\
& capacidades \\
\hline $16: 30$ a $18: 30$ & Conferencias \\
\hline $18: 30$ a $19: 00$ & Descanso para el café/Sesión de póster \\
\hline $19: 00$ a $20: 30$ & Mesa redonda. Situación de las Altas Capacidades en Europa \\
\hline
\end{tabular}

\begin{tabular}{|c|c|}
\hline \multicolumn{2}{|c|}{ Viernes $\mathbf{2 1}$ de junio de $\mathbf{2 0 1 9}$} \\
\hline 09:00 a $10: 30$ & Comunicaciones libres. Mesa de Intervención II \\
\hline $10: 30$ a $12: 00$ & Conferencias \\
\hline $12: 00$ a $12: 30$ & Descanso para el café/Sesión de póster \\
\hline $12: 30$ a $14: 00$ & Conferencias \\
\hline $16: 00$ a $17: 30$ & Comunicaciones libres. Mesa de Detección, Identificación y Evaluación \\
\hline $17: 30$ a $18: 00$ & Descanso para el café/Sesión de póster \\
\hline $18: 00$ a $19: 00$ & Conferencia de clausura \\
\hline $19: 00$ a $19: 30$ & Clausura \\
\hline
\end{tabular}




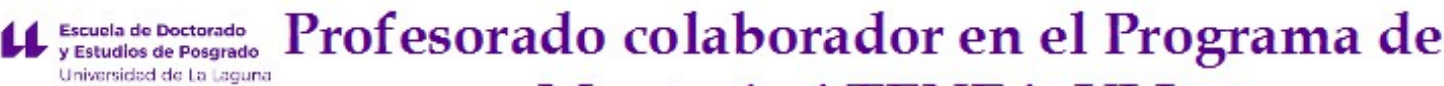 \\ Mentoría ATENEA-ULL}

aIACC.

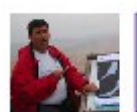
Ramón Casillas Ruiz Actividad El oulle de La Onotans o ol de Guímar, los grandes deslizamientos onstitr cionnles de los edificios 00 há nicos como los grandes responsubles del relieve de las Ishs Ca narias
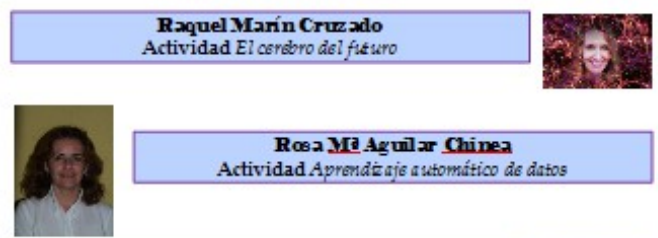

Rosa Ma Aguilar Chinea Actividad A prendét aje automático de distos
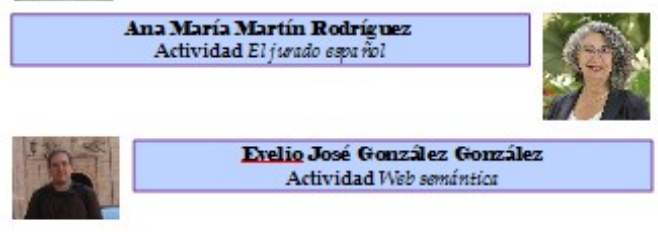

Exelio José Gronzález Gionzález Actividad Wab sonintic

Alberto Javier Báez García Actividad Claves po na el andilisis electoral

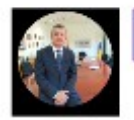

\section{Eduardo Bezares} Actividad Logíticas

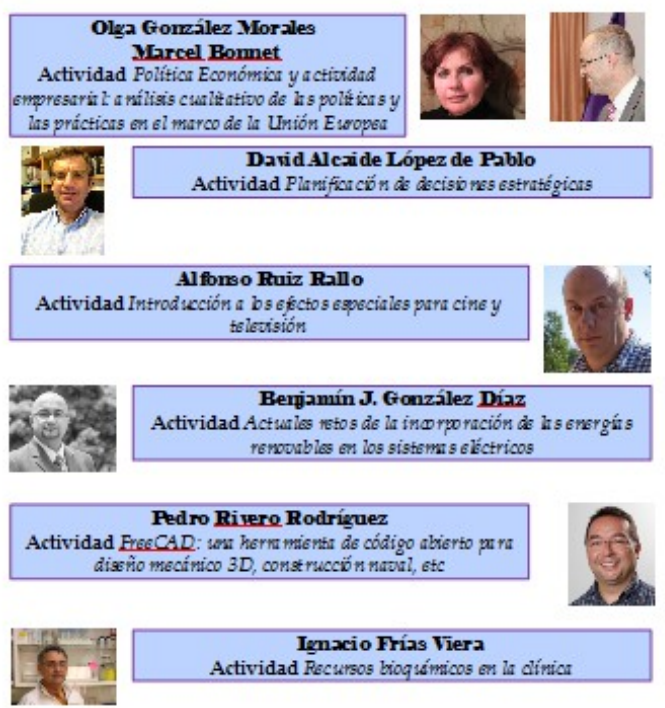

Tomás González Hernández

Actividad Emformedades newo degenerntivas; actualidat $d y$ perspectious

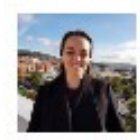

Yr Belén San Nicolás Santos Actividad Ident idad digital y proyscción professiona?

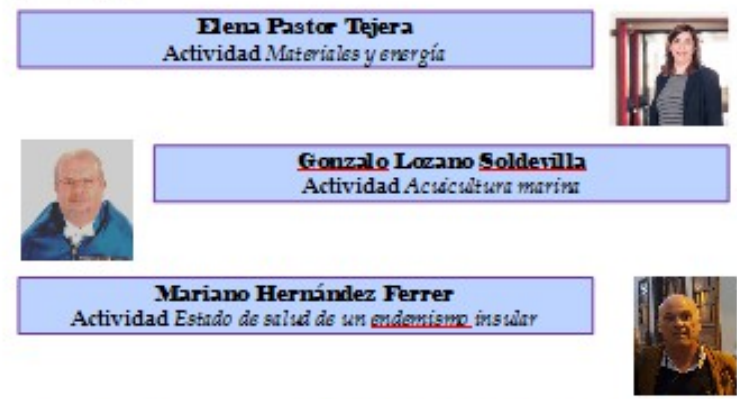

José David Mach ado Ponce Actividad 19 Proteins fic rescentes y sus apliancions on biomodicins.

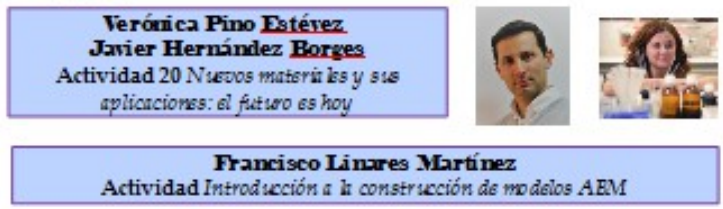

Vicente Mampel Zinata Hernández Actividad La Geografia en suproyección socioterritorit? conocimiento para ha interosnción com lestita rit

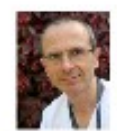

Eduardo Salido Ruiz

Actividad Enfsrmedsdes raras: invest ignndo lo excepcions? para entender lo habituat?

Manuel D. García Román
Actividad Propugnción, transformt cón n y yer mílisis del o baje

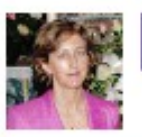

María Candelaria González Dáxila Actividad Avunce de ha Geometrín : desde Exclides a Rigmann

Teresa Gonzalez Pérez

Actividad Las mujeres on ha historia de in Educrción

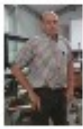

\section{Rigmann}

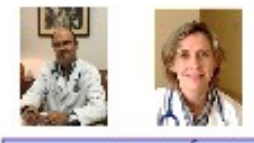

Cire Casanor

María del Valle Velasco Comzalez

Actividad Histo ria matienl de la EPOC

María Ángeles Alonso Rodríguez

Actividad Los mitos sobre in momoria: ¿qué nos dice in ciencia? 


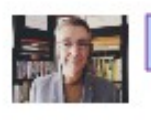

Fernando L. Rosa Gomzález Actividad Gros y so nido no linsal tras elorden de ha mision

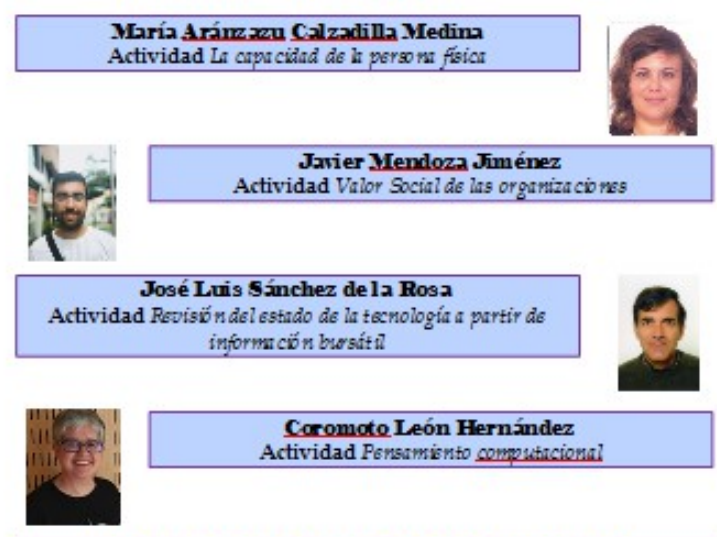

Alberto Damínguez, Iván Padróny Francesca Vitale Actividad Técnicns de inuestignción cerebra $l$ Algumas aplicaciones búsions y apliondas

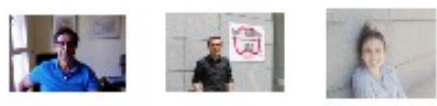

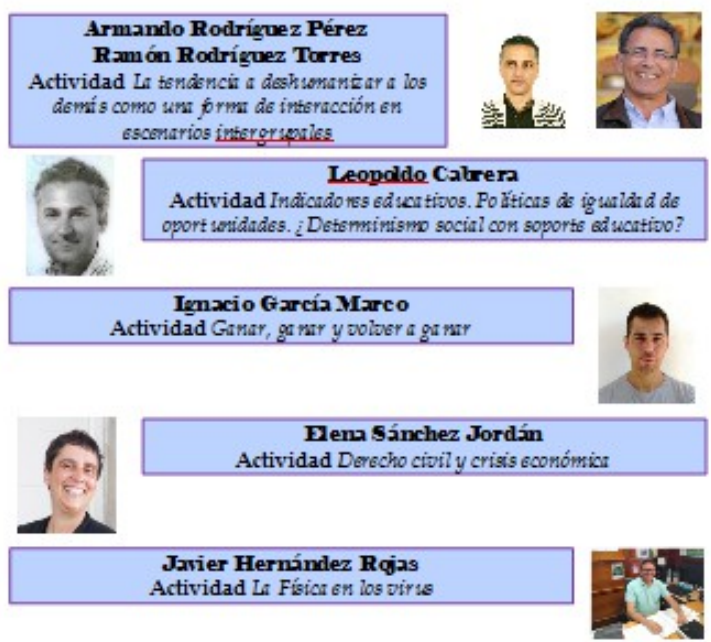

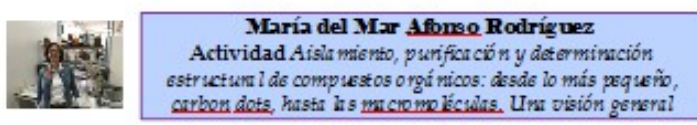

Marta María Domínguez Herrera Actividad Visitr al SEGAI
Fermando Pérez González

Actividad Variable Complja zs. Variable Ranl

José Antorio Ramos Arteaga

Actividad So rasr ha ciudad o cómo emprender desde las Humanidades

Hlfbnso Muñoz González

Actividad Fision de in Motsrin Condensa das. Más a há de ln ecuación de Schrödingerr

\begin{tabular}{c} 
Ciudalberto Hernández \\
Silvia Velázguez \\
Actividad Nueričóny sulud: al Sindrome Metrabólico \\
\hline
\end{tabular}

Raquel Lucía Pérez Brito
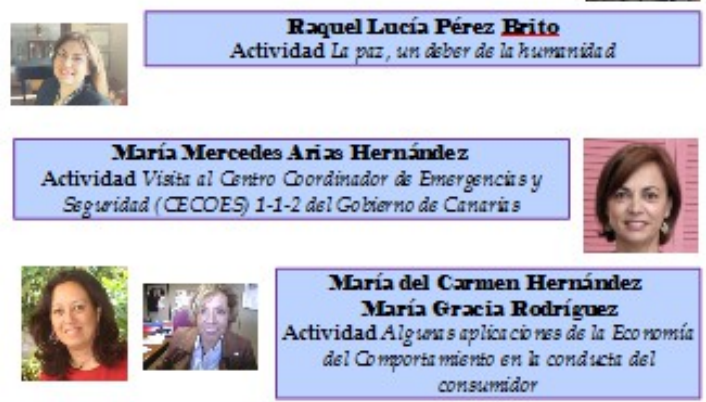

Rubí Nieves rodríguez Díaz

Raquel Blanes Zamora.

Actividad Reproducción asistial

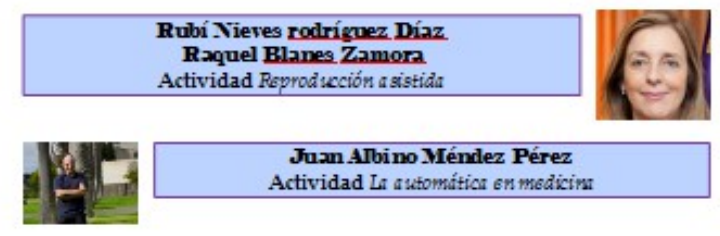

Agustín Valemruela Fernández Actividad VIRUS: uns amenrza pa na la humn nidad, y um área de fueuro para la medicina $y$ la ciencin en su conjiato
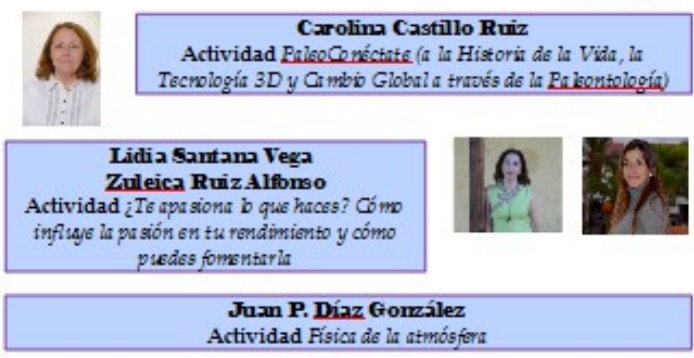

Rodrigo Trujille Gomz śle z Actividad Las Matemátions para $61 \mathrm{~s}$ XXI 


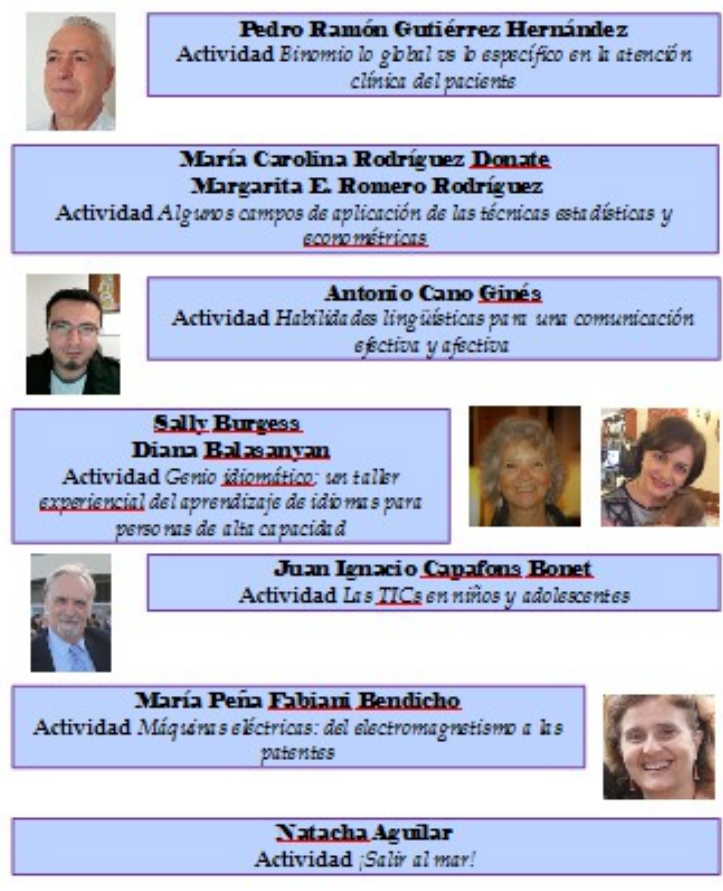

\section{Organizadores}
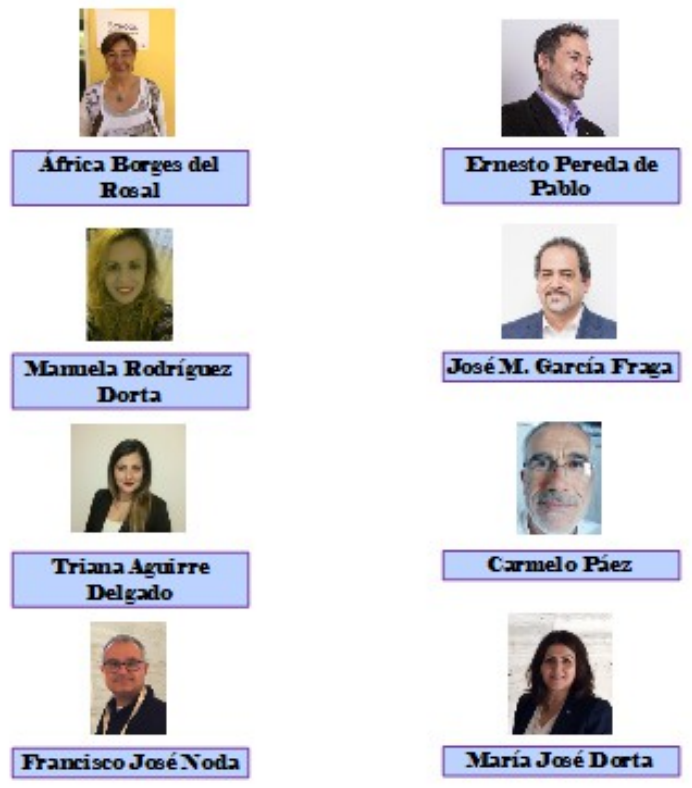

José M. García Fraga

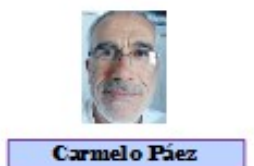

Carmelo Prez

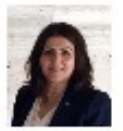

María José Dorta

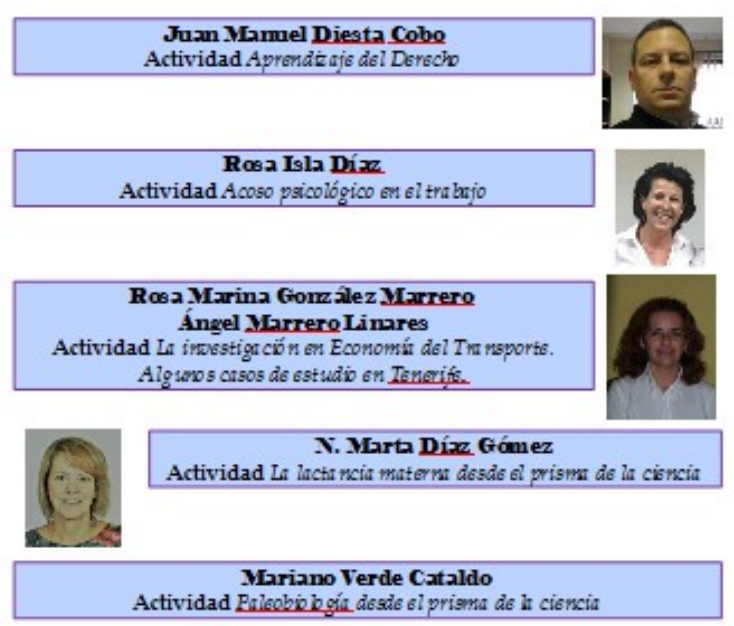

Daxid López Aguil xr

Actividad Trabajando on grupo en el contexto de ha enserinnza uenviersian rà

Véstor Capui

Actividad La naturalea no srbe de fision

\section{Conferencias Plenarias}

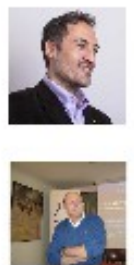

Ernesto Pereda de Pablo

Primera conferencia plenaria Aprendisndo del que subs: 6 cerdbro bien comechrdo

Dolores Valadez Sierra

Quinta conferencia plenaria Altss Grpaciala des en México 
